\title{
Implementation of one and three dimensional models for heat transfer coeffcient identification over the plate cooled by the circular water jets
}

\author{
Zbigniew Malinowski $^{1}$ (D) Agnieszka Cebo-Rudnicka ${ }^{1}$ - Beata Hadała ${ }^{1}$. \\ Artur Szajding ${ }^{1} \cdot$ Tadeusz Telejko $^{1}$
}

Received: 21 March 2017 / Accepted: 9 October 2017 / Published online: 23 October 2017

(C) The Author(s) 2017

\begin{abstract}
A cooling rate affects the mechanical properties of steel which strongly depend on microstructure evolution processes. The heat transfer boundary condition for the numerical simulation of steel cooling by water jets can be determined from the local one dimensional or from the three dimensional inverse solutions in space and time. In the present study the inconel plate has been heated to about $900{ }^{\circ} \mathrm{C}$ and then cooled by six circular water jets. The plate temperature has been measured by 30 thermocouples. The heat transfer coefficient and the heat flux distributions at the plate surface have been determined in time and space. The one dimensional solutions have given a local error to the heat transfer coefficient of about $35 \%$. The three dimensional inverse solution has allowed reducing the local error to about $20 \%$. The uncertainty test has confirmed that a better approximation of the heat transfer coefficient distribution over the cooled surface can be obtained even for limited number of thermocouples. In such a case it was necessary to constrain the inverse solution with the interpolated temperature sensors.
\end{abstract}

\section{List of symbols \\ ATD \\ Average temperature difference between mea- sured and computed temperature curves $\left({ }^{\circ} \mathrm{C}\right)$ \\ $B \quad$ Width of the heat transfer coefficient determi- nation part of the plate $(\mathrm{mm})$ \\ c $\quad$ Specific heat $[\mathrm{J} /(\mathrm{kg} \mathrm{K})]$ \\ $c_{a} \quad$ Specific heat of air $[\mathrm{J} /(\mathrm{kg} \mathrm{K})]$}

Zbigniew Malinowski

malinows@agh.edu.pl

Akademia Gorniczo-Hutnicza im Stanislawa Staszica w Krakowie, Kraków, Poland
$C_{s}(\tau) \quad$ Dimensionless scaling function defined by Eq. (11)

$E\left(p_{i}\right) \quad$ Dimensionless objective function defined by Eq. (13)

$F \quad$ Parameter defined by Eq. (14) $(\mathrm{K} / \mathrm{s})$

$g \quad$ Gravitational acceleration $\left(\mathrm{m} / \mathrm{s}^{2}\right)$

$G_{j} \quad$ Cubic shape function of the one dimensional element in time

$h\left(x_{2}, x_{3}, \tau\right) \quad$ Function defining heat transfer coefficient distribution in space and time $\left[\mathrm{W} /\left(\mathrm{m}^{2} \mathrm{~K}\right)\right]$

$h_{m}(\tau) \quad$ Function defining variation of the heat transfer coefficient maximum in time $\left[\mathrm{W} /\left(\mathrm{m}^{2} \mathrm{~K}\right)\right]$

$H \quad$ Characteristic length of the plate $(\mathrm{m})$

HTC Heat transfer coefficient $\left(\mathrm{W} /\left(\mathrm{m}^{2} \mathrm{~K}\right)\right)$

$\mathrm{HTC}_{\max } \quad$ Maximum value of the heat transfer coefficient $\left(\mathrm{W} /\left(\mathrm{m}^{2} \mathrm{~K}\right)\right)$

$\mathrm{HTC}_{\min } \quad$ Minimum value of the heat transfer coefficient $\left(\mathrm{W} /\left(\mathrm{m}^{2} \mathrm{~K}\right)\right)$

KT Number of elements in time

$L \quad$ Length of the heat transfer coefficient determination part of the plate $(\mathrm{mm})$

$N_{H T C} \quad$ Total number of the minimized parameters

$N_{i} \quad$ Cubic shape functions from serendipity family of the surface element

NP Number of temperature measurements performed by one sensor

NT Number of temperature sensors

$p_{i}, p_{i j} \quad$ Unknown parameters to be determined by minimizing the objective function $\left[\mathrm{W} /\left(\mathrm{m}^{2} \mathrm{~K}\right)\right]$ $R a \quad$ Rayleigh number, $R a=g \beta\left(T_{\mathrm{s}}-T_{\mathrm{a}}\right) H^{3} \rho_{\mathrm{a}} \mathrm{c}_{\mathrm{a}} /$ $\left(v_{\mathrm{a}} \lambda_{\mathrm{a}}\right)$

$\dot{q}\left(x_{i}, x_{j}, \tau\right) \quad$ Heat flux $\left(\mathrm{W} / \mathrm{m}^{2}\right)$

$S_{k} \quad$ Cooling chamber surface $\left(\mathrm{m}^{2}\right)$

$S_{S} \quad$ Plate surface $\left(\mathrm{m}^{2}\right)$

T Temperature $\left({ }^{\circ} \mathrm{C}\right)$ 


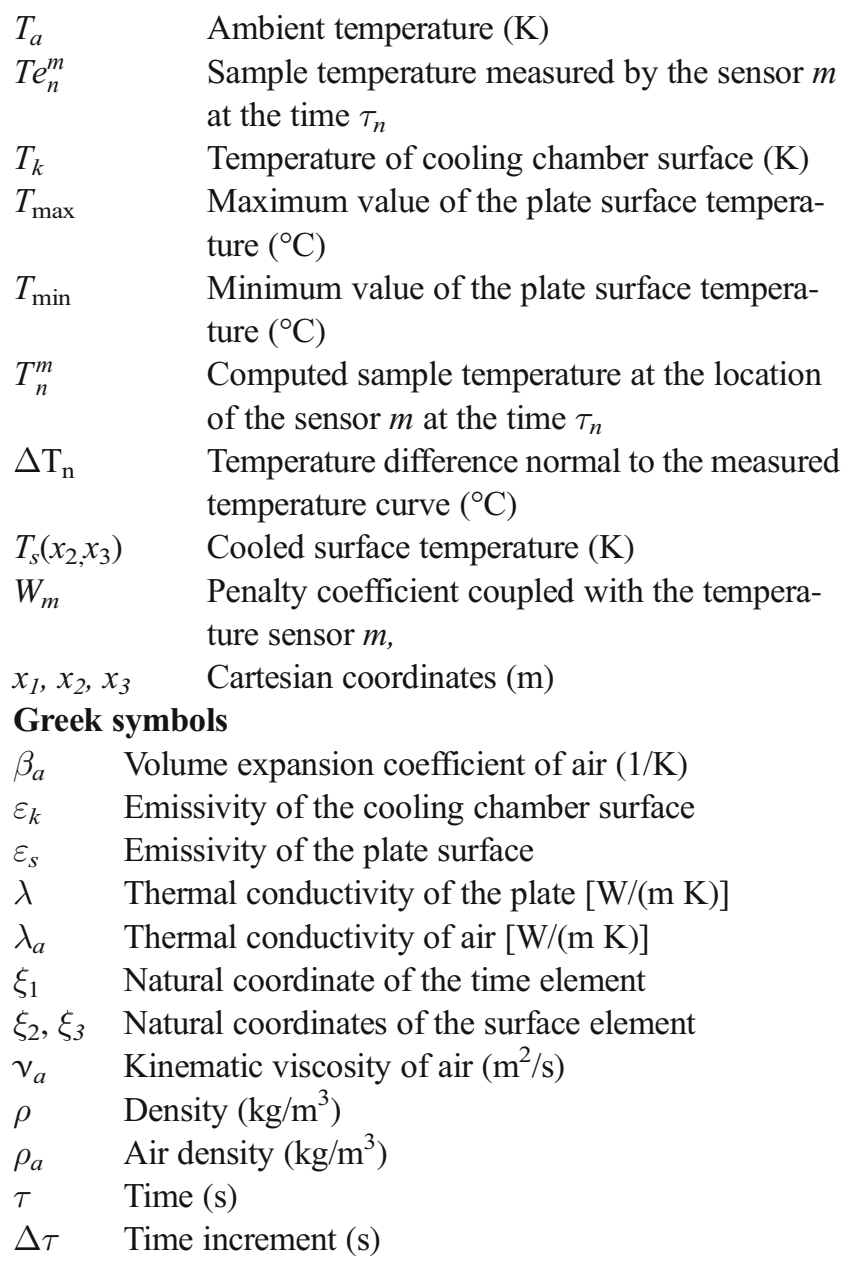

\section{Introduction}

Steel products are widely present in our everyday live. Specific properties of steel are needed for elements of structures such as buildings, bridges, scaffoldings etc. Essentially higher mechanical properties are required for elements of motor vehicles or tools. The quality and properties of steel are determined by the production process, in which the cooling processes play an important role. For example the jet cooling can be utilized during quenching processes as the most effective and flexible method of cooling [1].The topic of jet cooling is risen in many publications. It is so, because this type of cooling is widely utilized not only in the steel industry, but also in many other industrial applications for cooling gas turbine [2, 3], aircrafts engine, supersonic flight vehicles [4], electronic equipment [5,6] or divertor in fusion power plant [7].

In steel manufacturing process water cooling systems allows to develop advanced steel grades with demanded microstructures [8]. The main influence on the microstructure evolution processes in metals has temperature, cooling rate and cooling pattern [9] [10]. The desired rate of cooling is achieved by water sprays, water curtains or water jets applied to the hot metal surface [11]. The water flow rate and pressure can be changed in a wide range and it results in a very different heat transfer from the cooled metal to the cooling water. Numerical simulations have often been utilized to select proper values of the cooling parameters [12-14]. In such simulation the boundary conditions of heat transfer play an important role. Kim [15] has pointed out that the majority of experimental data is limited to the average in space heat flux or heat transfer coefficient. Experimental techniques such as array of microheaters [16], cooling of thin foil [17] or temperature oscillation IR thermography [18] cannot be used for measuring heat transfer coefficient distribution during cooling of metals from temperatures reaching $1000{ }^{\circ} \mathrm{C}$. Recent developments of jet impingement boiling have been widely discussed by Qiu et al. [19]. The researchers are mainly focused on steady state processes typical for heat exchangers. In such cases determination of heat flux at the cooled surface does not require inverse methods which utilize transient solutions to the heat conduction problem. However, for metallurgical processes the heat flux or the heat transfer coefficient (HTC) as functions of the cooled surface temperature under transient cooling are the most important. In order to identify the heat transfer coefficient or heat flux using the solution of the inverse heat conduction problem different models are developed. Beck [20] has presented an inverse method and successfully determined heat flux variation in time using measured temperature inside the cooled copper block. Singh et al. [21] have utilized the one dimensional finite element volume method for determining the total heat flux from the experimentally obtained data. It was necessary to make some simplification in the heat transfer model, such as an assumption of adiabatic boundary condition at the bottom surface of the steel plate or neglecting heat losses from the sidewalls of the plate. Implementation of the one dimension model can lead to the HTC determination errors which could reach $60 \%$ in comparison with the two-dimensional models [22]. Further, it has been recognized that the heat transfer during water cooling varies at the cooled surface in space and time [23, 24]. In a number of publications two-dimensional inverse heat conduction model are used to identify heat flux and heat transfer coefficient [25-29]. Jha et al. [27] and Sarkar et al. [28] have assumed some simplifications such as adiabatic conditions at the surfaces that are not being cooled by jet impingement. Such simplifications were acceptable under the conditions of the experimental procedure. Although, identifying the HTC or heat flux for steel industry, we should provide the experimental conditions similar to those that exist during the real processes. For example the plate thickness has an influence on the wetting zone development on the cooled metal surface. [30]. In such cases, it is reasonable to use numerical models which allow modeling transient three dimensional cooling. 
One of the first solutions to such a problem has been reported in [31] and [32]. Huang and Wang [31] have presented implementation of CFX4.2 commercial software for determining HTC distribution over the cooled surface. The solution was presented only for the simulated temperature sensor indications. Similar solutions to the simulated temperature readings have been reported by Kim et al. [32], and Zhou et al. [33]. However, convergence is much easier to achieve for simulated temperature readings, especially if large number of temperature reading points is taken to build the objective function. In the case of measured temperatures the number of thermocouples is limited due to its influence on the plate temperature and limitation of the physical experiment. The measurement errors have essential influence on the inverse solution accuracy. Thus, the number thermocouples and its arrangement over the HTC determination domain are important. In the paper three dimensional solutions to the plate cooling with six water jets have been obtained using 30 thermocouples. Uncertainty of the inverse solutions have been analysed taking into account the experimental errors and limitations of the inverse method. The arrangement of the thermocouples has been studied.

\section{Experimental setup}

Schematic of the plate heating and cooling assembly has been presented in Fig. 1. The plate $8 \mathrm{~mm}$ thick mounted to the automatic feeder arm was placed horizontally. The plate made of inconel was heated in the electrical furnace to a uniform temperature of about $900{ }^{\circ} \mathrm{C}$., Fig. 2. The plate was $300 \mathrm{~mm}$ long and $210 \mathrm{~mm}$ wide. The water jet nozzles have been located $390 \mathrm{~mm}$ above the plate, approximately at the centre of the HTC determination domain $B=90 \mathrm{~mm}$ wide and $L=100 \mathrm{~mm}$ long, Fig. 2. The plate was cooled by six water jets. The nozzle diameter was $2 \mathrm{~mm}$. The water temperature was $18{ }^{\circ} \mathrm{C}$ and the total water flow rate was $10.4 \mathrm{dm}^{3} / \mathrm{min}$. The water flow was measured with the turbine flow meter having the accuracy $\pm 0.5 \%$. The $\mathrm{K}$ type thermocouples with $80 \mu \mathrm{m}$ diameter wires protected by a $500 \mu \mathrm{m}$ diameter sheath were used to measure the plate temperature. Measurements were recorded at a frequency of $10 \mathrm{~Hz}$ by the data acquisition system equipped with a noise reduction filter having an accuracy class of $\pm 0.5{ }^{\circ} \mathrm{C}$. Due to implementation of the noise reduction filter the thermocouple noise was negligible. The accuracy of the thermocouples was equal to $\pm 0.4 \%$ of the measured temperature. The maximum error of the thermocouple having accuracy class $\pm 0.4 \%$ at temperature $1000{ }^{\circ} \mathrm{C}$ is about $\pm 4{ }^{\circ} \mathrm{C}$. In addition to that an error of $3{ }^{\circ} \mathrm{C}$ has resulted from the gauge accuracy class connecting thermocouples to data acquisition system. Thus, based on the accuracy specified by the producers the maximum error of the measured temperature was $7{ }^{\circ} \mathrm{C}$. The plate temperature was measured by 30 thermocouples located $2 \mathrm{~mm}$ below the cooled surface. The thermocouples have been manually inserted into the holes $0.5 \mathrm{~mm}$ in diameter drilled from the bottom of the plate to a depth of $6 \mathrm{~mm}$. It was important to fit particular thermocouple with a particular hole taking into account deviations from the nominal diameter. Polishing carefully the thermocouple

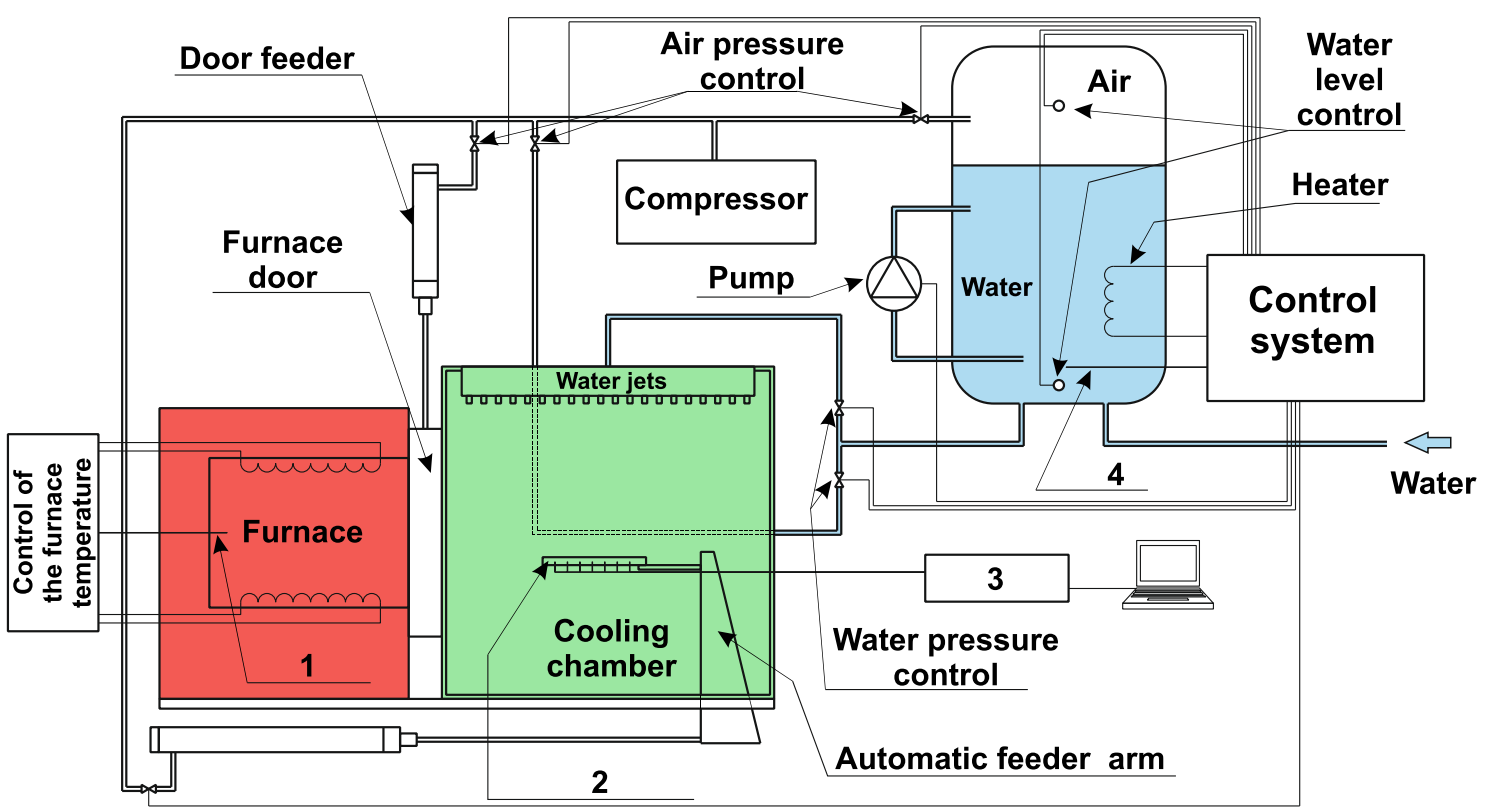

Fig. 1 Schematic of the plate heating and cooling setup. 1 - Thermocouple, 2 - Plate with thermocouples, 3 - Plate temperature measurement system, 4 Water temperature measurement system 
Fig. 2 The inconel plate cooled by six water jets and the coordinate system employed in the inverse solutions to the heat conduction problem in plate. All dimensions are given in $\mathrm{mm}$
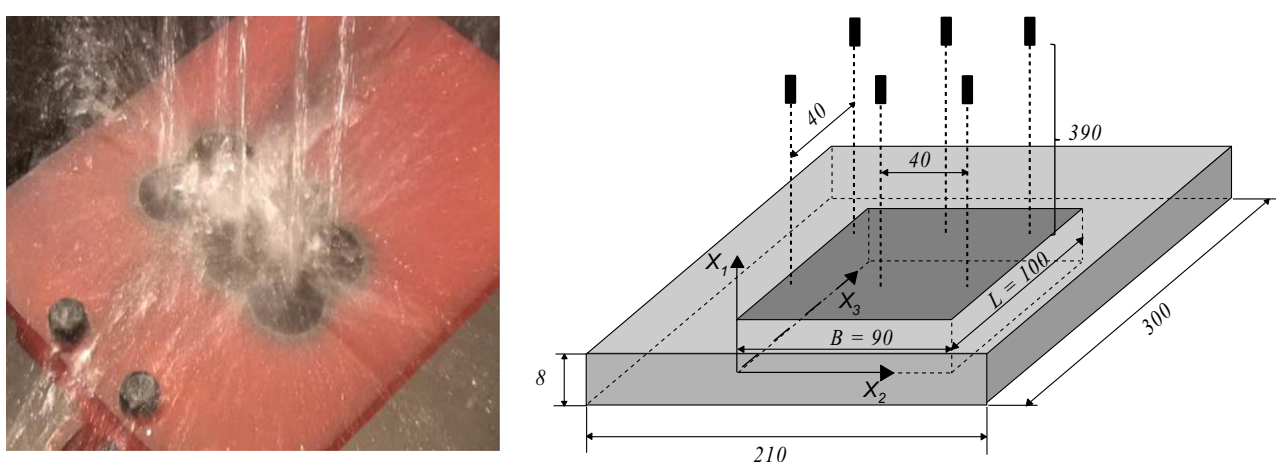

sheath it was possible to ensure the desired fit. Next, using a small punch a local plastic deformation near the thermocouple has been applied. Plastic deformation of the plate fixes the thermocouple in the hole. Finally the thermocouples have been connected to the data acquisition system and the plate has been mounted to the automatic feeder arm and placed in the furnace for heating. Oxidation and sintering makes the thermocouple connection with the plate nearly perfect.

The thermocouples locations over the HTC determination domain have been shown in Fig. 5. Some uncertainty of the temperature measurement exists and is mainly related to the unknown exact location of the thermocouple tip. Further, since 30 thermocouples have been inserted into holes drilled in the plate it may have some influence on the plate temperature field. For that reasons the accuracy of the temperature measurement has been estimated using the finite element simulation of cooling of the plate with the thermocouples. The results of the simulated temperature measurement errors have been given in Section 5.1.

\section{Forward problem formulation}

The inverse solution to the HTC requires dedicated heat conduction model of the plate cooling. The heat conduction model should have sufficient accuracy under low computation time. The description of the finite element model employed to solve Eq. (1) has been given by Malinowski et al. [34]. The solution strategy developed by Hadała et al. [35] has been implemented.

The plate temperature $T\left(x_{1}, x_{2}, x_{3}, \tau\right)$ shown in Fig. 2 has been calculated from the finite element solution to the heat conduction equation:

$$
\begin{aligned}
& \frac{\partial}{\partial x_{1}}\left(\lambda \frac{\partial T}{\partial x_{1}}\right)+\frac{\partial}{\partial x_{2}}\left(\lambda \frac{\partial T}{\partial x_{2}}\right)+\frac{\partial}{\partial x_{3}}\left(\lambda \frac{\partial T}{\partial x_{3}}\right)-\rho c \frac{\partial T}{\partial \tau} \\
& \quad=0
\end{aligned}
$$

The inconel alloy has been selected for the experiment to avoid the influence of the latent heat of the phase transformation in solid state on the HTC determination.

Zero heat fluxes have been assumed at the side surfaces of the HTC determination domain for the plate temperature computations:

$$
\begin{aligned}
& \dot{q}\left(x_{1}, x_{2}=0, x_{3}, \tau\right)=-\lambda \frac{\partial T}{\partial x_{2}}=0 \\
& \dot{q}\left(x_{1}, x_{2}=B, x_{3}, \tau\right)=-\lambda \frac{\partial T}{\partial x_{2}}=0 \\
& \dot{q}\left(x_{1}, x_{2}, x_{3}=0, \tau\right)=-\lambda \frac{\partial T}{\partial x_{3}}=0 \\
& \dot{q}\left(x_{1}, x_{2}, x_{3}=L, \tau\right)=-\lambda \frac{\partial T}{\partial x_{3}}=0
\end{aligned}
$$

The HTC determination domain is placed in the middle of the plate to avoid the influence of the plate edges cooling on the inverse solution. However, during water cooling the water flows over the plate and the temperature vary in the direction perpendicular to the HTC determination border. The assumed boundary conditions neglect this effect and introduce some error to the HTC determination near the border. The error is the highest at the HTC maximum and can be estimated as 50\% of the error resulting from the implementation of the one dimensional (1D) heat conduction model in the inverse solution at the thermocouple located at the border. It will be shown in chapter 5.2 that this error reaches $15 \%$ of the HTC value.

At the bottom of the plate heat flux resulting from plate cooling in the chamber has been specified:

$$
\begin{aligned}
\dot{q}\left(x_{1}=0, x_{2}, x_{3}, \tau\right)= & 5.67 \cdot 10^{-8} \frac{T_{s}^{4}\left(x_{2}, x_{3}\right)-T_{k}^{4}}{\frac{1}{\varepsilon_{s}}+\frac{S_{s}}{S_{k}}\left(\frac{1}{\varepsilon_{k}}-1\right)} \\
& +\frac{\lambda_{a}}{H} 0.27 R a^{\frac{1}{4}}\left(T_{s}\left(x_{2}, x_{3}\right)-T_{a}\right)
\end{aligned}
$$

The Eq. (6) takes into account radiation to the chamber walls (first term) and convection heat loses to the air (second term). The heat loss to the air has been calculated from 
the Nusselt number formula developed by S. Ostrach and given in [36]. The cooling chamber is made of a stainless steel and has the surface $S_{k}=4.33 \mathrm{~m}^{2}$. The chamber surface temperature $T_{k}=T_{a}$ and emissivity $\varepsilon_{k}=0.2$ have been assumed in computations. The sample surface was $S_{s}=0.134 \mathrm{~m}^{2}$. Air conductivity $\lambda_{a}$ and other air properties [36] necessary to calculate the Rayleigh number $R_{a}$ have been evaluated at the average fluid temperature $T_{f}=\left(T_{s}+\right.$ $\left.T_{a}\right) / 2$. The plate has been cooled in the chamber in air only in order to determine emissivity of the sample surface at $x_{1}=0$ which is not cooled by water. The sample temperature has been measured by thermocouples. The inverse solution to the one dimensional heat conduction in the plate has given the sample emissivity $\varepsilon_{s}=0.52$ [24].

The temperature at the bottom plate surface varies mainly due to water cooling at the top surface. It results in variable heat flux over the surface specified by Eq. (6). The heat transfer from the bottom plate surface is mainly due to radiation and the effective heat transfer coefficient calculated from Eq. (6) varies from 150 to $20 \mathrm{~W} /\left(\mathrm{m}^{2} \mathrm{~K}\right)$. The convective component is low and varies from 10 to $2 \mathrm{~W} /\left(\mathrm{m}^{2} \mathrm{~K}\right)$. The numerical tests have shown that for the plate $8 \mathrm{~mm}$ thick the inverse solution at the upper surface has low sensitivity to the boundary condition at the bottom surface. The possible inaccuracy of the heat flux determination at the bottom surface resulting from the inaccuracy in the emissivity determination and in convective heat losses has minor influence on the HTC determination at the water cooled surface. It is due to the temperature sensor location near the upper surface and large difference in the HTC value between upper and bottom surface.

Inconel thermal conductivity and specific heat have been determined as functions of temperature based on data published in [37]. Curve fitting to the data have given the following equations:

$c(T)=451.8+0.1 \cdot T+1.986123 \cdot 10^{-4} \cdot T^{2}$

$\lambda(T)=14.468+0.0139 \cdot T+2.98 \cdot 10^{-6} \cdot T^{2}$

$\rho=8470$

Eqs. (7) and Eq. (8) are valid for temperatures of $0 \leq T \leq 1000{ }^{\circ} \mathrm{C}$. For the assumed temperature range the inconel density does not depend on temperature and constant value has been employed in computations.

For the finite element solver tests and generating the simulated temperature readings for the determination of the uncertainty of the inverse solutions the HTC distribution over the cooled surface varying in time has been specified:

$h\left(x_{2}, x_{3}, \tau\right)=h_{m}(\tau) \sum_{k=1}^{k=6}\left[e^{-\left(\left(\frac{x_{2}-x_{2}^{k}}{C_{s}(\tau)}\right)^{2}+\left(\frac{x_{3}-x_{3}^{k}}{C_{s}(\tau)}\right)^{2}\right)}\right]$
In Eq. (3) $C_{s}(\tau)$ is a scaling function:

$C_{s}(\tau)=20\left[1+\left(\frac{2 \tau-60}{60}\right)^{2}\right]$

The test function (10) has been developed using trial and error method for modeling plate cooling with six water jets. The function contains several parameters controlling the HTC distribution in time and space. The coordinates: $\left(x_{2}^{k} ; x_{3}^{k}\right)$ given in Table 1 specify the water jet location over the HTC determination domain. The water jets move at the plate surface from the nominal position of the nozzle axis. For that reason the jet axis slightly differs from the nozzle axis.

The function $C_{\mathrm{s}}(\tau)$ models the HTC maxim location in time and the HTC distribution around the jet axis. The Eq. (11) specifies the HTC maxim at $\tau=30 \mathrm{~s}$ and limits the diameter of high HTC values to $20 \mathrm{~mm}$. The function $h_{m}(\tau)$ controls variation of the HTC maximum value in time. The cubicspline functions have been utilized to describe $h_{m}(\tau)$ variation in time. The cooling time has been divided into two periods. The cubic-spline parameters have been given in Table 2 .

For example the HTC distribution over the cooled surface at $\tau=30 \mathrm{~s}$ resulting from Eq. (10) has been shown in Fig. 3. The HTC distribution is similar to that expected during plate cooling with six water jets.

The HTC variations in time at selected points have been indicated in Figs. 8 and 9 as "Exact" curves. At the beginning of cooling Eq. (10) simulates the HTC distribution for film boiling. The HTC maximum is modeled at $\tau=22 \mathrm{~s}$ and HTC reaches $6 \mathrm{~kW} /\left(\mathrm{m}^{2} \mathrm{~K}\right)$. At the end of cooling the HTC drops to a level typical for natural convection boiling with the $\mathrm{HTC}=1 \mathrm{~kW} /\left(\mathrm{m}^{2} \mathrm{~K}\right)$. The boundary condition $(10)$ has given the plate surface temperature field shown in Fig. 4 for $\tau=30 \mathrm{~s}$. After $30 \mathrm{~s}$ the plate temperature has dropped to about $60{ }^{\circ} \mathrm{C}$ below nozzles. The highest plate temperature about $120{ }^{\circ} \mathrm{C}$ has been obtained between nozzles.

The finite element solver employed in the inverse solutions has been compared with the high accuracy finite element solution to the plate cooling, see Table 3 . The reference solution Re-Mo has been obtained for 7920 elements with the linear shape functions. The plate temperature variations at 30 points

Table 1 Location of the jet axis and the nozzle axis over the HTC determination domain

\begin{tabular}{lllllll} 
Jet/nozzle axis coordinate & \multicolumn{6}{l}{ Jet number, $k$} \\
\cline { 2 - 7 } & 1 & 2 & 3 & 4 & 5 & 6 \\
\hline$x_{2}, \mathrm{~mm}$ & $15 / 5$ & $15 / 5$ & $55 / 45$ & $55 / 45$ & $85 / 85$ & $85 / 85$ \\
$x_{3}, \mathrm{~mm}$ & $25 / 30$ & $75 / 70$ & $25 / 30$ & $75 / 70$ & $25 / 30$ & $75 / 70$
\end{tabular}


Table 2 The cubic-spline parameters applied for $h_{m}(\tau)$ interpolation in time

\begin{tabular}{|c|c|c|c|c|c|}
\hline \multicolumn{2}{|l|}{ First node, $\tau=0 \mathrm{~s}$} & \multicolumn{2}{|c|}{ Second node, $\tau=30 \mathrm{~s}$} & \multicolumn{2}{|l|}{ Third node, $\tau=60$} \\
\hline$h_{m}(\tau), \mathrm{W} /\left(\mathrm{m}^{2} \mathrm{~K}\right)$ & $\partial h_{m}(\tau) / \partial \tau \mathrm{W} /\left(\mathrm{m}^{2} \mathrm{~K} \mathrm{~s}\right)$ & $h_{m}(\tau), \mathrm{W} /\left(\mathrm{m}^{2} \mathrm{~K}\right)$ & $\partial h_{m}(\tau) / \partial \tau \mathrm{W} /\left(\mathrm{m}^{2} \mathrm{~K} \mathrm{~s}\right)$ & $h_{m}(\tau), \mathrm{W} /\left(\mathrm{m}^{2} \mathrm{~K}\right)$ & $\partial h_{m}(\tau) / \partial \tau \mathrm{W} /\left(\mathrm{m}^{2} \mathrm{~K} \mathrm{~s}\right)$ \\
\hline 100 & 0 & 10,000 & 0 & 400 & $-1 / 30$ \\
\hline
\end{tabular}

located $2 \mathrm{~mm}$ below the water cooled surface, Fig. 5, obtained from the Re-Mo solution has been assumed as the simulated temperature sensors indications. Next, the plate temperature has been computed using reduced finite element solvers with the nonlinear shape functions. Three solutions obtained for 16 , 25 and 36 prism elements have been compared to the reference model in Table 3. The average temperature difference (ATD) between the Re-Mo solution and the reduced models: H4-Mo, H5-Mo and H6-Mo have been computed from:

$$
\mathrm{ATD}=\sqrt{\frac{1}{N T N P} \sum_{m=1}^{N T} \sum_{n=1}^{N P}\left[\frac{T e^{n m}-T\left(p_{i}\right)^{n m}}{\sqrt{1+\left(\frac{\Delta T e^{n m}}{\Delta \tau}\right)^{2}}}\right]^{2}}
$$

In Eq. (12) $T_{e}^{n m}$ denotes sample temperature obtained from Re-Model at the sensor $n$ and at the time $\tau_{m}$. In Eq. (12) the term in brackets defines the temperature difference $\Delta \mathrm{T}_{\mathrm{n}}$ between two curves: $T(\tau)$ and $T_{e}(\tau)$ always normal to the $T_{e}(\tau)$ curve [35].

The reduced three dimensional (3D) models have given very good accuracy of the plate temperature simulations. The maximum temperature difference $\Delta \mathrm{T}_{\mathrm{n}}$ is below $1{ }^{\circ} \mathrm{C}$ and all the models can be employed in inverse solutions. However, in the inverse solutions to the measured temperatures higher HTC values can be encountered and the accuracy of the H4-Mo solver may not be sufficient. Taking into account a compromise between accuracy and computation time

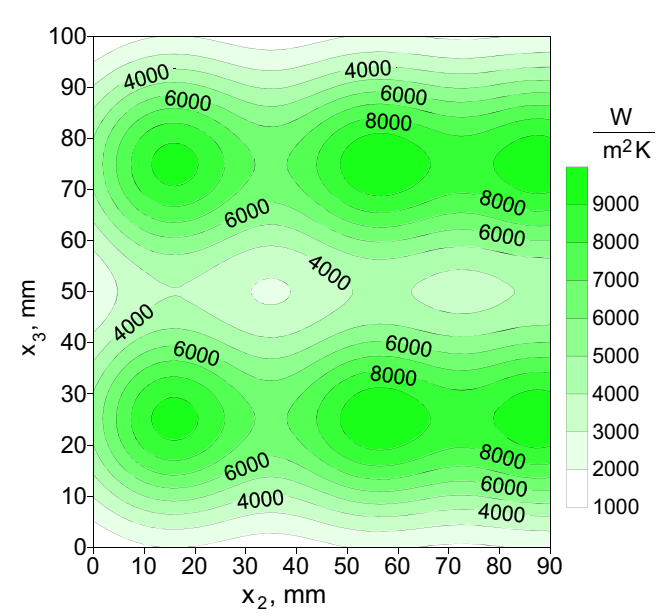

Fig. 3 The HTC distribution over the cooled surface defined by Eq. (10) for $\tau=30 \mathrm{~s}$. $\mathrm{HTC}_{\max }=9908, \mathrm{HTC}_{\min }=1119 \mathrm{~W} /\left(\mathrm{m}^{2} \cdot \mathrm{K}\right)$ the H5-Mo solver with 576 degrees of freedom has been selected for the inverse solutions.

\section{The inverse problem formulation}

The method of the HTC determination over the cooled plate surface proposed by Malinowski et al. [34] has been utilized in the present study. The inverse solutions to the HTC distribution over the plate surface have been obtained by minimizing the objective function developed by Hadała et al. [35]:

$$
\begin{aligned}
& E\left(p_{i}\right)=\frac{1}{N T N P} \sum_{m=1}^{N T} \sum_{n=1}^{N P} \\
& \left\{\left[\frac{1}{\sqrt{1+\left(\frac{\Delta T e^{n m}}{\Delta \tau}\right)^{2}}}\left(\frac{T e^{n m}-T\left(p_{i}\right)^{n m}}{T e^{n m}}\right)\right]^{2}+W_{m}\left(\frac{\frac{\Delta T e^{n m}}{\Delta \tau}-\frac{\Delta T\left(p_{i}\right)^{n m}}{\Delta \tau}}{F^{n m}}\right)^{2}\right\}
\end{aligned}
$$

The term $F^{\mathrm{n} m}$ has been specified as follows:

$$
\begin{gathered}
F^{n m}=\frac{\Delta T e^{n m}}{\Delta \tau} \text { for }\left|\frac{\Delta T e^{n m}}{\Delta \tau}\right|>1 \\
F^{n m}=1 \text { for }\left|\frac{\Delta T e^{n m}}{\Delta \tau}\right| \leq 1
\end{gathered}
$$

The objective function (13) defines the dimensionless temperature difference between measured and computed temperatures always normal to the measured temperature curve. The dimensionless temperature difference has been extended with

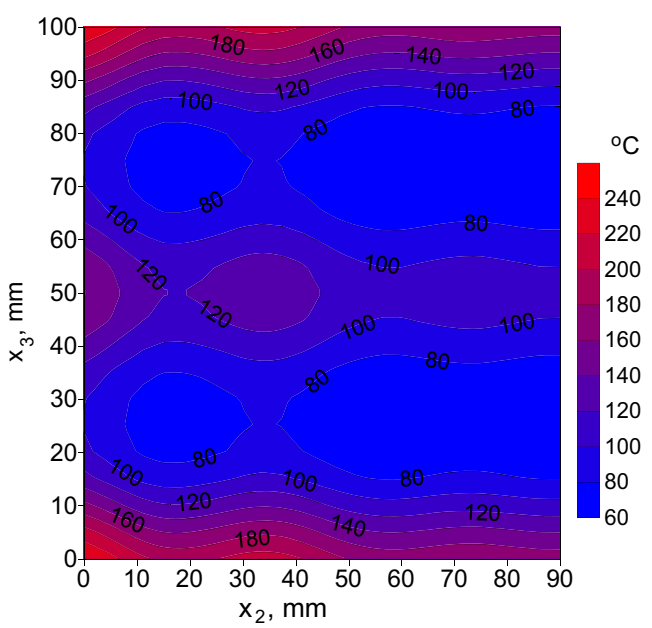

Fig. 4 The temperature distribution over the cooled surface at $\tau=30 \mathrm{~s}$ for the HTC defined by Eq. (10). $\mathrm{T}_{\max }=240, \mathrm{~T}_{\min }=61{ }^{\circ} \mathrm{C}$ 
Table 3 Accuracy of the finite element models in forward simulations of the plate cooling

\begin{tabular}{|c|c|c|c|c|c|}
\hline \multirow{2}{*}{\multicolumn{2}{|c|}{ Parameter }} & \multicolumn{4}{|c|}{ Heat conduction model } \\
\hline & & Re-Mo & H4-Mo & H5-Mo & H6-Mo \\
\hline \multicolumn{2}{|c|}{ Number of elements in $x_{1}$ direction } & 22 & 1 & 1 & 1 \\
\hline \multicolumn{2}{|c|}{ Number of elements in $x_{2}$ direction } & 18 & 4 & 5 & 6 \\
\hline \multicolumn{2}{|c|}{ Number of elements in $x_{3}$ direction } & 20 & 4 & 5 & 6 \\
\hline \multicolumn{2}{|c|}{ Degrees of freedom } & 9177 & 400 & 576 & 784 \\
\hline \multicolumn{2}{|l|}{ Time increment $\Delta \tau, \mathrm{s}$} & 0.05 & 0.5 & 0.5 & 0.5 \\
\hline \multirow[t]{3}{*}{ Error to the Re-Model, ${ }^{\circ} \mathrm{C}$} & $\Delta \mathrm{T}_{\max }$ & 0 & 10.5 & 11.6 & 13.5 \\
\hline & $\Delta \mathrm{T}_{\mathrm{n}}$ & 0 & 0.5 & 0.5 & 0.6 \\
\hline & ATD & 0 & 0.23 & 0.28 & 0.26 \\
\hline
\end{tabular}

the norm of the dimensionless temperature gradients difference. It has been shown [35] that the objective function (13) reduces in inverse solutions the HTC fluctuations resulting from the HTC maxima moving over the cooled surface in time.

The HTC distribution over the cooled surface has been approximated by surface elements with cubic shape functions $N_{i}$ :

$h\left(x_{2}, x_{3}, \tau\right)=\sum_{i=1}^{12} N_{i}\left(\xi_{2}, \xi_{3}\right) \sum_{j=1}^{4} G_{j}\left(\xi_{1}\right) p_{i j}$

Cubic shape functions $N_{i}$ from serendipity family have the following form [38]:

For corner nodes: $n=1,4,7,10$ and $\xi_{1 n}= \pm 1$ and $\xi_{2 n}= \pm 1$

$N_{n}=\frac{1}{32}\left(1+\xi_{1} \xi_{1 n}\right)\left(1+\xi_{2} \xi_{2 n}\right)\left(9 \xi_{1}^{2}+9 \xi_{2}^{2}-10\right)$

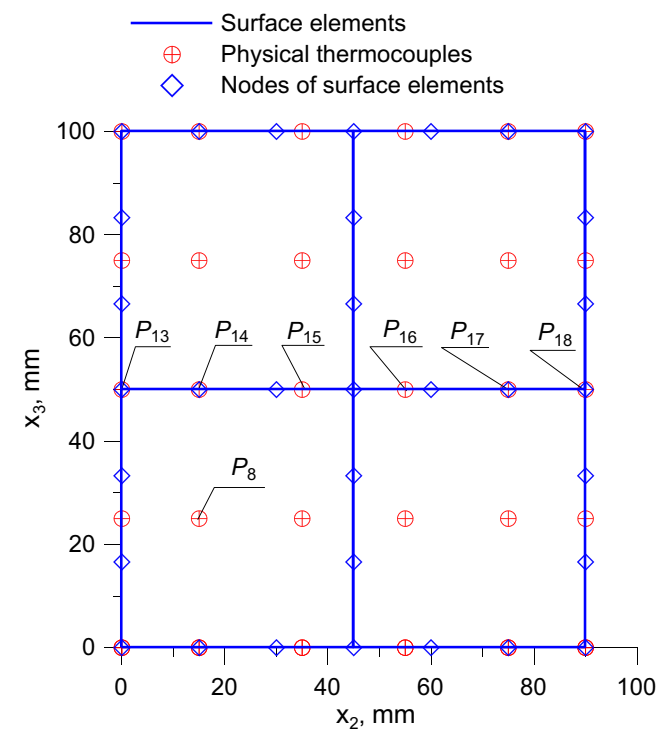

Fig. 5 The location of thermocouples and division of the cooled surface into 4 surface elements employed in the HTC model V4
For side nodes: $n=2,3,8,9$ and $\xi_{1 n}= \pm 1 / 3$ and $\xi_{2 n}= \pm 1$

$N_{n}=\frac{9}{32}\left(1+\xi_{2} \xi_{2 n}\right)\left(1+\xi_{1}^{2}\right)\left(1+9 \xi_{1} \xi_{1 n}\right)$

For side nodes: $n=5,6,11,12$ and $\xi_{2 n}= \pm 1 / 3$ and $\xi_{1 n}= \pm 1$

$N_{n}=\frac{9}{32}\left(1+\xi_{1} \xi_{1 n}\right)\left(1+\xi_{2}^{2}\right)\left(1+9 \xi_{2} \xi_{2 n}\right)$

where $\xi_{2}, \xi_{3}$ are natural coordinates of the surface element on the interval $(-1,1)$.

The cooled surface has been divided into surface elements. The HTC distribution in time at nodes of surface elements has been interpolated by the cubic shape functions [38]:

$G_{1}=\left(1-\xi_{1}\right)\left(9 \xi_{1}^{2}-1\right) / 16$

$G_{2}=9\left(1-3 \xi_{1}\right)\left(1-\xi_{1}^{2}\right) / 16$

$G_{3}=9\left(1+3 \xi_{1}\right)\left(1-\xi_{1}^{2}\right) / 16$

$G_{4}=\left(1+\xi_{1}\right)\left(9 \xi_{1}^{2}-1\right) / 16$

where $\xi_{1}$ denotes dimensionless time:

$\xi_{1}=\frac{2 \tau-\tau_{1}-\tau_{2}}{\tau_{2}-\tau_{1}}$

In Fig. 5 division of the HTC determination domain into four surface elements has been presented. In this case the HTC variations at 33 nodes have to be determined in order to describe the HTC distribution over the cooled surface. For the inverse solution tests the time of cooling has been divided into $\mathrm{KT}=6$ periods. The HTC variations in time at nodes of surface elements have been approximated by the cubic shape functions. It has given the total number of the unknown HTC coefficients $\mathrm{N}_{\mathrm{HTC}}=33 *(6 * 3+1)=627$ in the case of the HTC model V4, Fig. 5.

The division of the cooled surface into nine elements, presented in Fig. 6 as the HTC model V9, results in 


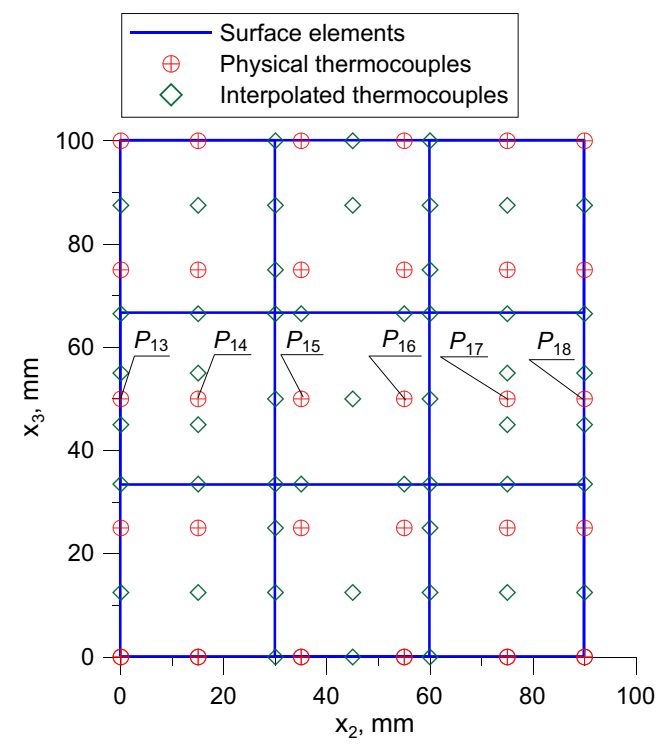

Fig. 6 The location of thermocouples and division of the cooled surface into 9 surface elements employed in the HTC model V9

$\mathrm{N}_{\mathrm{HTC}}=64 *(6 * 3+1)=1216$ unknown parameters. The set of unknown parameters $p_{i j}$ can be grouped into the vector $p_{i}$ which has to be determined from the minimum condition of the objective function (13). Minimization of the dimensionless objective function (13) allows determining the HTC distribution over the cooled surface for low and high temperatures and temperature's gradients varying in space and time. The solution strategy for such problems has been developed by Hadała et al. [35].

\section{Uncertainty of the inverse solution}

The inverse solution to the HTC distribution in space and time can exhibit essential deviation from a real boundary condition. This problem results mainly from the temperature measurement errors, limited number of the temperature sensors. Further uncertainty is related to the formulation of the boundary condition model and the definition of the objective function. For that reasons the uncertainty tests have been performed and the boundary condition resulting from Eq. (10) has been searched.

\subsection{Estimation of the temperature measurement errors.}

One of the important problems resulting from temperature measuring with the use of inserted thermocouples is the influence of the thermocouples on the plate temperature and the location of the thermocouple tip. The temperature measurement errors resulting from using thermocouples has been simulated with a high accuracy finite element model. In the finite element model the thermocouple having a diameter of $0.5 \mathrm{~mm}$ has been modeled as a square bar $0.5 \mathrm{~mm}$ in the cross section.
The thermocouples length in the plate was $6 \mathrm{~mm}$. Four elements with the linear shape functions have been employed in the thermocouple's cross section. In the thickness of the plate 17 elements have been employed. The element size at the cooled surface was $0.02 \mathrm{~mm}$. The total number of elements was 10,472 . Only a quarter of the plate with the thermocouple $P_{8}$ surrounded by 8 thermocouples shown in Fig. 5 has been simulated. This part of the plate is cooled by one water jet. Location of the simulated water jet has been shown in Fig. 3 . The thermophysical properties of elements simulating the thermocouples have been assumed as a material having a conductivity $1 \mathrm{~W} /(\mathrm{m} \mathrm{K})$, a density $2000 \mathrm{~kg} / \mathrm{m}^{3}$ and a specific heat $800 \mathrm{~J} /(\mathrm{kg} \mathrm{K})$. The $\mathrm{K}$ type thermocouple is composed of two metallic wires insulated with the silicon dioxide $\mathrm{SiO}_{2}$. In the FEM model the thermocouple structure as well as the thermophysical properties of the components of the thermocouple has been simplified. The properties of the material simulating the thermocouple have been chosen similar to the properties of the silicon dioxide [36]. The assumed simplifications result in some overestimation of the thermocouple influence on the plate temperature. The boundary conditions at the plate surfaces have been described in chapter 3 . The results of simulations of the plate temperature with and without thermocouples have been presented in Fig. 7.

The temperature variations at point $P_{8}, P_{8 \mathrm{~T}}$ and $P_{8 \mathrm{~S}}$ in time have been shown for the solid plate, for the plate with one thermocouple $P_{8}$ only and for the plate with 9 thermocouples. The point $P_{8}$ is located at $x_{1}=6 \mathrm{~mm}$, point $P_{8 \mathrm{~T}}$ at $x_{1}=5.75 \mathrm{~mm}$, and point $P_{8 \mathrm{~S}}$ at $x_{1}=8 \mathrm{~mm}$. The point $P_{8 \mathrm{~S}}$ is located at the water cooled surface above the thermocouple. The point $P_{8 \mathrm{~T}}$ indicates the most probable location of the thermocouple junction in the orifice $6 \mathrm{~mm}$ long indicated as point $P_{8}$. The solid plate temperature and the plate temperatures with one or nine thermocouples shown in Fig. 7 are nearly identical. However, some influence of the thermocouple on the plate temperature has been noticed and summarized in Table 4 .

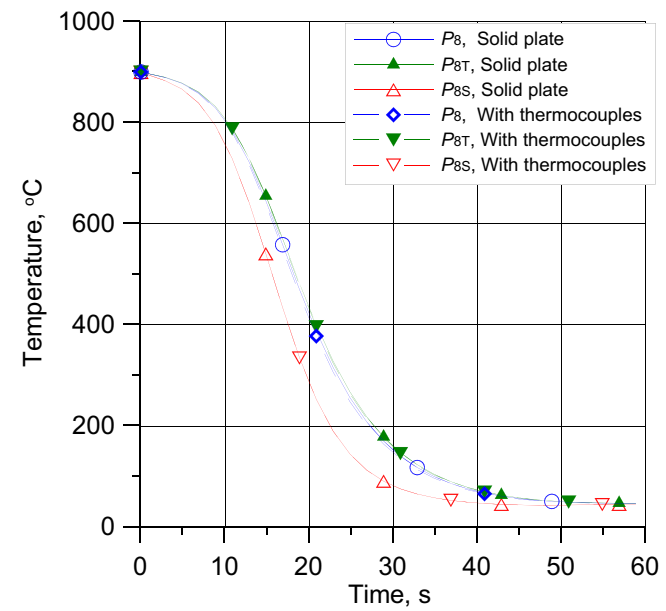

Fig. 7 The plate temperature variations at selected points in the solid plate and in the plate with thermocouples 
Table 4 Temperature at selected points of the solid plate and the plate with thermocouples

\begin{tabular}{|c|c|c|c|c|}
\hline \multirow[t]{2}{*}{ Time, $\mathrm{s}$} & \multirow[t]{2}{*}{ Plate } & \multicolumn{3}{|c|}{ Temperature at point, ${ }^{\circ} \mathrm{C}$} \\
\hline & & $P_{8}$ & $P_{8 \mathrm{~T}}$ & $P_{8 \mathrm{~S}}$ \\
\hline \multirow[t]{3}{*}{15} & solid & 645.3 & 654.9 & 540.6 \\
\hline & 9 thermocouples, $\Delta \mathrm{T}$ & -7.3 & -2.9 & -0.5 \\
\hline & 1 thermocouple, $\Delta \mathrm{T}$ & -7.3 & -2.9 & -0.5 \\
\hline \multirow[t]{3}{*}{30} & solid & 140.7 & 147.6 & 75.8 \\
\hline & 9 thermocouples, $\Delta \mathrm{T}$ & -5.0 & -2.2 & -0.2 \\
\hline & 1 thermocouple, $\Delta \mathrm{T}$ & -5.0 & -2.2 & -0.2 \\
\hline \multirow[t]{3}{*}{45} & solid & 56.7 & 58.2 & 44.0 \\
\hline & 9 thermocouples, $\Delta \mathrm{T}$ & -1.0 & -0.5 & -0.1 \\
\hline & 1 thermocouple, $\Delta \mathrm{T}$ & -1.0 & -0.5 & -0.1 \\
\hline
\end{tabular}

The plate temperature difference between solid plate and the plate with thermocouple depends on time. Due to a lower conductivity of the thermocouple the temperature at the thermocouple junction is lower about $3{ }^{\circ} \mathrm{C}$ at $15 \mathrm{~s}$ and vanishes as the rate of cooling decreases. The thermocouple has negligible influence on the plate surface temperature, point $P_{85}$. The solid layer of $2 \mathrm{~mm}$ above the thermocouples has reduced the thermocouple influence and the vertical thermocouples do not change boiling condition at the plate surface. Notice, that 9 thermocouples have the same effect on the plate temperature as the one thermocouple only.

Thus the use of 30 thermocouples does not increase the temperature measurement errors. Further, it can be concluded, that the simulated maximum value of the temperature measurement error at the thermocouple junction varies from 3 to $7{ }^{\circ} \mathrm{C}$ and is nearly the same as the thermocouple accuracy specified by the producer. Moreover, the simulated temperature readings obtained from Re-Mo and employed for the inverse solution tests deviate from the H5-Mo solution of about $11^{\circ} \mathrm{C}$, Table 3 . Thus, the temperature measurement errors have been incorporated into uncertainty tests.

\subsection{The one dimensional inverse solutions}

The inverse solutions require determination of the temperature field in the cooled sample. The computation time is high if three dimensional heat conduction models are employed. Distribution of the heat flux over the cooled surface of the plate can be also determined from the local inverse solutions at the thermocouple locations. In such a case the heat conduction model is simplified to 1D and the computation time is essentially lower. However, the question is about the accuracy of the solution. The answer to this problem is not obvious and depends on the cooling conditions. For that reason 1D inverse solution at selected points shown in Fig. 5 have been compared to the exact boundary condition specified at the plate surface.
The obtained 1D inverse solutions have been presented in Figs. 8 and 9 . The one dimensional solutions at points: $P_{13}, \ldots, P_{18}$ are generally similar to the prescribed boundary condition. The ATD between the one dimensional inverse solutions (D1-Inv.) and the simulated sensors indications is low and do not exceeds $0.5^{\circ} \mathrm{C}$, Table 5 . The maximum temperature difference $\Delta \mathrm{T}_{\mathrm{n}}$ is also low at a level of $2{ }^{\circ} \mathrm{C}$. However, the error to the HTC at $30 \mathrm{~s}$ varies from 10 to $34 \%$, Table 5 .

A lowest error of $10 \%$ has been obtained at point $P_{14}$ and the highest at point $P_{13}$. At all points the HTC is higher from the prescribed boundary condition. It is due to heat conduction in $x_{2}$ and $x_{3}$ directions from hotter to colder parts of the plate, Fig. 4. In one dimensional solution the plate temperature drop is due to the heat flux in $x_{1}$ direction only. It results in overestimation of the HTC at points having higher temperature and underestimation of the HTC at colder places.

\subsection{Three dimensional inverse solutions}

\subsubsection{The boundary condition model V4}

For the inverse solution test simulated temperature readings of 30 physical thermocouples have been obtained using the test function (10) as the boundary condition in the finite element model of the inconel plate cooling. High accuracy Re-Model with linear elements of 9177 degrees of freedom has been employed. But in the inverse solution the reduced H5-Model with the nonlinear shape functions of 576 degrees of freedom has been employed. In the direct simulations of the plate cooling the reduced model has given an ATD of $0.3{ }^{\circ} \mathrm{C}$ with the maximum deviation $\Delta \mathrm{T}_{\max }$ of $11^{\circ} \mathrm{C}$ to the data obtained from Re-Model. Thus, the inverse solution tests have been performed for the simulated temperature readings showing essential differences to the reduced H5-Model. It has been estimated, that the experimental errors to the measured temperatures are not higher, Table 4 .

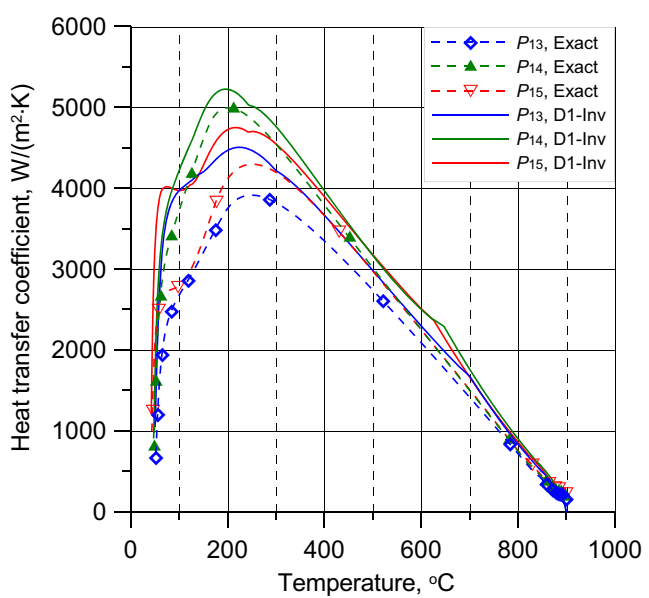

Fig. 8 The one dimensional inverse solutions to the HTC variations at points: $P_{13}, P_{14}$ and $P_{15}$ compared to the exact data 


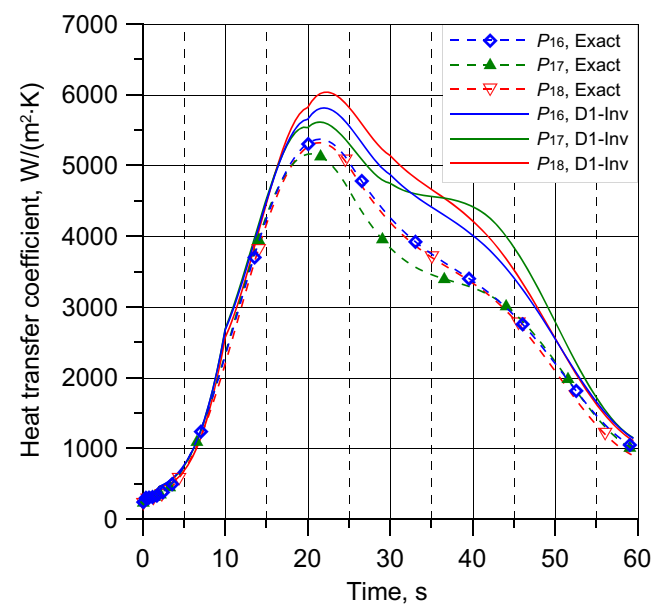

Fig. 9 The one dimensional inverse solutions to the HTC variations at points: $P_{16}, P_{17}$ and $P_{18}$ compared to the exact data

The inverse solution to the simulated temperature sensor has converged to an ATD of $0.4{ }^{\circ} \mathrm{C}$ with a $\Delta \mathrm{T}_{\mathrm{n}}$ of $2.2{ }^{\circ} \mathrm{C}$, Table 6. In Fig. 10 the temperature variations obtained from the inverse solution (V4-Inv) has been compared to the simulated temperature sensors indications (Exact) at selected points. The temperature curves shown in Fig. 10 are nearly identical but the HTC distributions do not agree as well with the prescribed boundary condition, Figs. 11 and 12 . The maximum error to the exact solution at point $P_{15}$ has reached $34 \%$, Table 6. The errors to the exact HTC at selected points are as high as those obtained from the local one dimensional solution. The starting point necessary for the minimization of the objective function (13) has been generated from the local one dimensional inverse solutions at nodes of surface elements [35]. The distribution of the HTC at $\tau=30 \mathrm{~s}$ assumed as starting point has been shown in Fig. 13.

The ATD at staring point was $2.5^{\circ} \mathrm{C}$ with the maximum deviation $\Delta \mathrm{T}_{\mathrm{n}}=13^{\circ} \mathrm{C}$. The objective function minimization has reduced the ATD essentially to a level of $0.4{ }^{\circ} \mathrm{C}$ with the maximum deviation $\Delta \mathrm{T}_{\mathrm{n}}=2.2{ }^{\circ} \mathrm{C}$. However, at selected points error to the exact HTC remained due to a low number of degrees of freedom in the HTC model V4.

Table 5 Parameters of the one dimensional inverse solutions to the specified boundary condition (10)

\begin{tabular}{lllllll}
\hline Parameter & \multicolumn{2}{l}{ Point: } & & & & \\
\cline { 2 - 7 } & $P_{13}$ & $P_{14}$ & $P_{15}$ & $P_{16}$ & $P_{17}$ & $P_{18}$ \\
\hline $\begin{array}{l}\text { Error to the exact HTC } \\
\text { at } \tau=30 \mathrm{~s}\end{array}$ & $34 \%$ & $10 \%$ & $32 \%$ & $13 \%$ & $24 \%$ & $22 \%$ \\
$\mathrm{ATD},{ }^{\circ} \mathrm{C}$ & 0.53 & 0.55 & 0.32 & 0.33 & 0.32 & 0.33 \\
$\Delta \mathrm{T}_{\mathrm{n}},{ }^{\circ} \mathrm{C}$ & 2.0 & 2.1 & 1.1 & 0.5 & 0.5 & 0.5 \\
\hline
\end{tabular}

Table 6 Parameters of the 3D inverse solution utilizing the HTC model V4 to the specified boundary condition (10)

\begin{tabular}{lllllll}
\hline Parameter & \multicolumn{2}{l}{ Point: } & & & & \\
\cline { 2 - 6 } & $P_{13}$ & $P_{14}$ & $P_{15}$ & $P_{16}$ & $P_{17}$ & $P_{18}$ \\
\hline $\begin{array}{l}\text { Error to the exact HTC } \\
\quad \text { at } \tau=30 \mathrm{~s}\end{array}$ & $21 \%$ & $12 \%$ & $34 \%$ & $22 \%$ & $28 \%$ & $27 \%$ \\
$\mathrm{ATD},{ }^{\circ} \mathrm{C}$ & 0.43 & & & & & \\
$\Delta \mathrm{T}_{\mathrm{n}}{ }^{\circ} \mathrm{C}$ & 2.2 & & & & & \\
\hline
\end{tabular}

\subsubsection{The boundary condition model V9}

The HTC distribution at the cooled surface in the HTC model V9 has been approximated by 9 surface elements with cubic shape functions from serendipity family. The division of the cooled surface into elements has been shown in Fig. 6. Each element has 12 nodes. Four nodes are located at element's corners and 8 nodes at element's sides, two nodes at each side. Since 9 elements have been utilized for the HTC approximation over the cooled surface, it has given 64 nodes at which the HTC values have to be determined from the minimum of the objective function. The number of physical thermocouples is much lower than the number of degrees of freedom. In such a case the inverse solution uncertainty can be high. On the other hand the HTC variation over the cooled surface is high during plate cooling and larger number of elements should give better solution. To resolve this problem the additional temperature sensors shown in Fig. 6 as interpolated thermocouples have been added to the physical thermocouples. It has allowed extending the temperature sensors to 81 .

The temperature readings at interpolated sensors have been obtained from the approximation of the nearest four thermocouples indications at a particular time. Four node elements

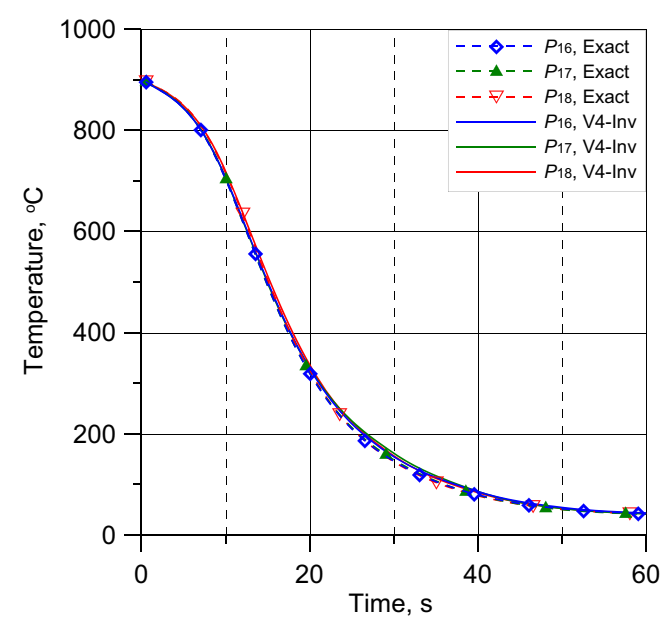

Fig. 10 The inverse solution obtained from the HTC model V4 to the temperature variations at points: $P_{16}, P_{17}$ and $P_{18}$ compared to the exact data 


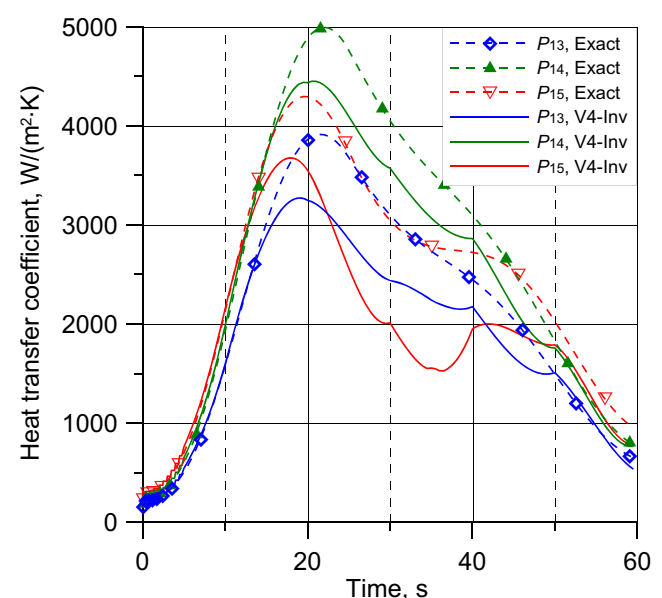

Fig. 11 The inverse solutions obtained from the HTC model V4 at points: $P_{13}, P_{14}$ and $P_{15}$ compared to the exact data

with the linear shape functions shown in Fig. 14 have been used in the approximation. The interpolated thermocouples locations have been selected based on numerical tests in order to achieve a low error of interpolation and to ensure at least 12 temperature sensors for each surface element.

The accuracy of the interpolated thermocouples indications have been determined based on numerical test. Cooling of the plate shown in Fig. 4 has been modeled. At the upper plate surface boundary condition given by Eq. (10) has been specified. At the bottom surface of the plate boundary conditions for cooling in chamber has been prescribed, Eq. (6). At side surfaces of the plate zero heat fluxes have been assumed. From the direct simulation of the plate cooling the temperature variations at 81 temperature sensors shown in Fig. 6 as physical and interpolated thermocouples have been obtained. The temperature sensor indications $2 \mathrm{~mm}$ below the water cooled surface have been recorded. These indications have been assumed as "exact" temperature readings. In the second test

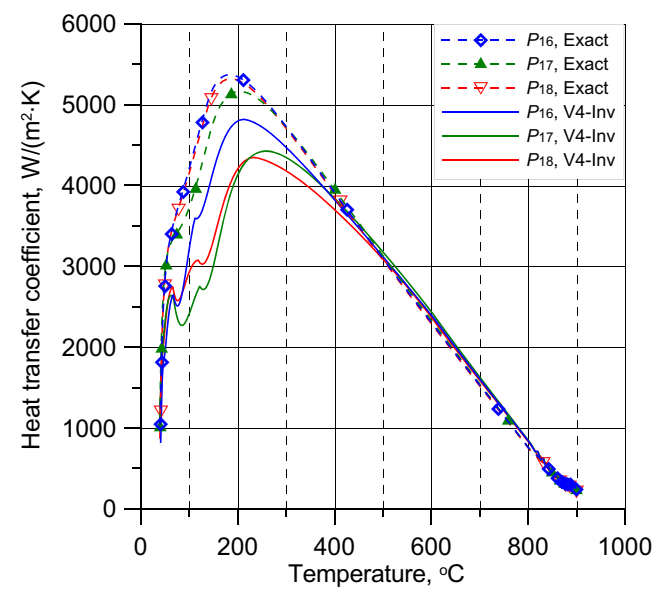

Fig. 12 The inverse solutions obtained from the HTC model V4 at points: $P_{16}, P_{17}$ and $P_{18}$ compared to the exact data

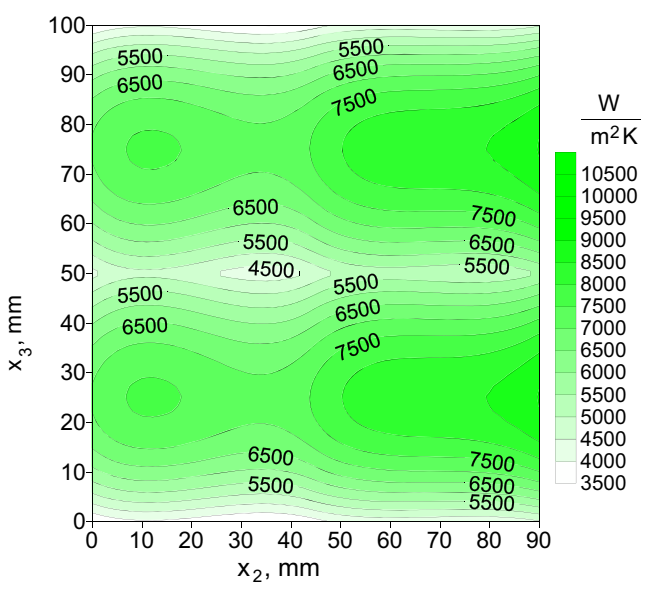

Fig. 13 The HTC distribution over the cooled surface at $\tau=30 \mathrm{~s}$ obtained from local 1D solutions at nodes of the HTC model V4. $\mathrm{HTC}_{\max }=9030$, $\mathrm{HTC}_{\min }=3455 \mathrm{~W} /\left(\mathrm{m}^{2} \cdot \mathrm{K}\right)$

only temperature readings at 30 points denoted as "physical thermocouples" have been obtained from the simulation of the plate cooling for the same boundary conditions. Since simulated "physical thermocouples" are located at linear element nodes, Fig. 14, readings of the rest of temperature sensors have been readily obtained from interpolation of the nodal values. The obtained set of 81 sensors readings which combine "exact" and interpolated sensors have been compared with the "exact" temperature readings. The average temperature difference (ATD) between simulated temperature readings and the "exact" temperature readings was below $0.5{ }^{\circ} \mathrm{C}$, with the maximum deviation $\Delta \mathrm{T}_{\mathrm{n}}=1.5^{\circ} \mathrm{C}$. In Fig. 15 the "exact" and the interpolated temperature sensors indications at three points: $P_{1}\left(x_{2}=45 ; x_{3}=0\right), P_{2}\left(x_{2}=45\right.$;

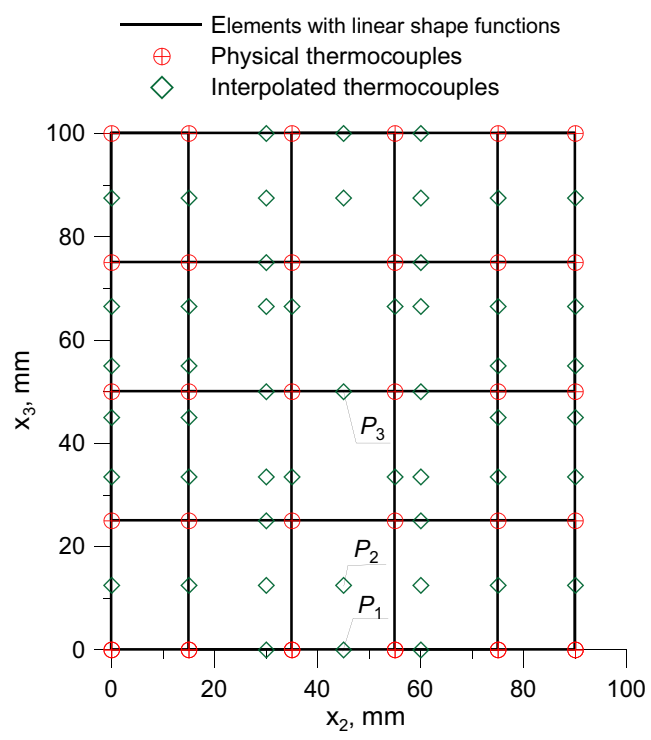

Fig. 14 The mesh of surface elements with linear shape functions employed for the determination of temperature at interpolated sensors locations 


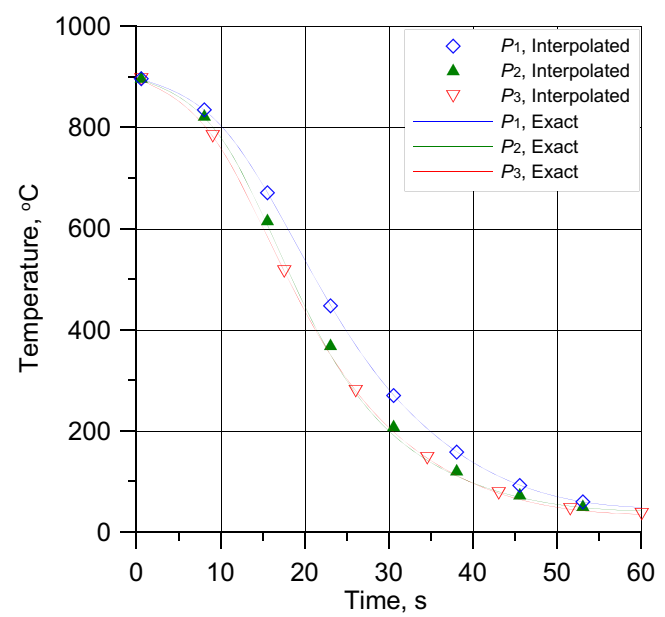

Fig. 15 Comparison between the exact and interpolated temperature sensors indications

$\left.x_{3}=12.5\right)$ and $P_{3}\left(x_{2}=45 ; x_{3}=50\right)$ have been shown. The differences are at the level of temperature measurements errors. In Table 7 exact and interpolated sensors indications at three points shown in Fig. 14 have been given. The interpolation error $\Delta \mathrm{T}$ depends on the temperature sensor location and the rate of cooling in a similar way as the thermocouple error. Thus, the developed method of the temperature sensor approximation has the accuracy comparable to the physical thermocouple located $2 \mathrm{~mm}$ below the cooled surface for the considered cooling conditions.

The minimization of the objective function (10) has been started from the prior solution obtained from the local 1D solution at the surface element nodes. In the case of the HTC model V9 the ATD at staring point was $3.2^{\circ} \mathrm{C}$ with the maximum deviation $\Delta \mathrm{T}_{\mathrm{n}}=11^{\circ} \mathrm{C}$. The objective function minimization has reduced the ATD to $0.27^{\circ} \mathrm{C}$ with the maximum deviation $\Delta \mathrm{T}_{\mathrm{n}}=0.8^{\circ} \mathrm{C}$, Table 8 .

The maximum error of the HTC approximation at selected points has dropped to $19 \%$, Table 8 . The distributions of the HTC at selected point have been compared to the exact data in Figs. 16 and 17.

Table 7 Exact and interpolated temperature sensor indications at selected points of the solid plate

\begin{tabular}{llrrr}
\hline Time, $\mathrm{s}$ & Sensor type & \multicolumn{3}{c}{ Temperature at point, ${ }^{\circ} \mathrm{C}$} \\
\cline { 3 - 5 } & & \multicolumn{1}{c}{$P_{1}$} & \multicolumn{1}{c}{$P_{2}$} & \multicolumn{1}{c}{$P_{3}$} \\
\hline \multirow{2}{*}{15} & Exact & 686.5 & 626.1 & 602.1 \\
& Interpolated, $\Delta \mathrm{T}$ & -0.4 & 6.8 & -0.5 \\
30 & Exact & 281.5 & 199.8 & 206.7 \\
& Interpolated, $\Delta \mathrm{T}$ & -0.5 & 16.2 & -0.5 \\
45 & Exact & 96.9 & 71.7 & 67.5 \\
& Interpolated, $\Delta \mathrm{T}$ & -0.4 & 3.7 & -0.3 \\
\hline
\end{tabular}

Table 8 Parameters of the 3D inverse solution utilizing the HTC model V9 to the specified boundary condition (10)

\begin{tabular}{lllllll}
\hline Parameter & \multicolumn{2}{l}{ Point: } & & & & \\
\cline { 2 - 6 } & $P_{13}$ & $P_{14}$ & $P_{15}$ & $P_{16}$ & $P_{17}$ & $P_{18}$ \\
\hline $\begin{array}{l}\text { Error to the exact HTC } \\
\text { at } \tau=30 \mathrm{~s}\end{array}$ & $15 \%$ & $19 \%$ & $0.3 \%$ & $14 \%$ & $12 \%$ & $14 \%$ \\
ATD, ${ }^{\circ} \mathrm{C}$ & 0.27 & & & & & \\
$\Delta \mathrm{T}_{\mathrm{n}},{ }^{\circ} \mathrm{C}$ & 0.8 & & & & & \\
\hline
\end{tabular}

In comparison to the HTC model V4 essentially better solution has been given by the HTC model V9. The improvement of the solution accuracy is clearly visible for lower surface temperatures below the HTC maximum.

The inverse solutions to the HTC at the cooled surface at $\tau=30 \mathrm{~s}$ has been presented in Figs. 18 and 19 for the HTC model V4 and V9, respectively. The locations of the HTC maxima have been correctly identified in both solutions. In the case of the HTC model V4 error to the HTC maximum is only $3.5 \%$ but the HTC minimum is largely overestimated and the error has reached $98 \%$. For the HTC model V9 a local error to the HTC maximum is $18 \%$ and to the HTC minimum $25 \%$.

In Figs. 20 and 21 average, over the cooled surface the HTC and heat flux, as functions of the average surface temperature has been compared to the exact data. A prior estimation of the HTC and heat flux obtained from local 1D inverse solution at surface element nodes has given acceptable accuracy. The HTC model V9 has given nearly exact final solution. Thus, in the case of complicated distribution of the HTC over the cooled surface inverse solution accuracy can be improved for limited number of thermocouples. However, the temperature field must be constrained in the inverse solution with the

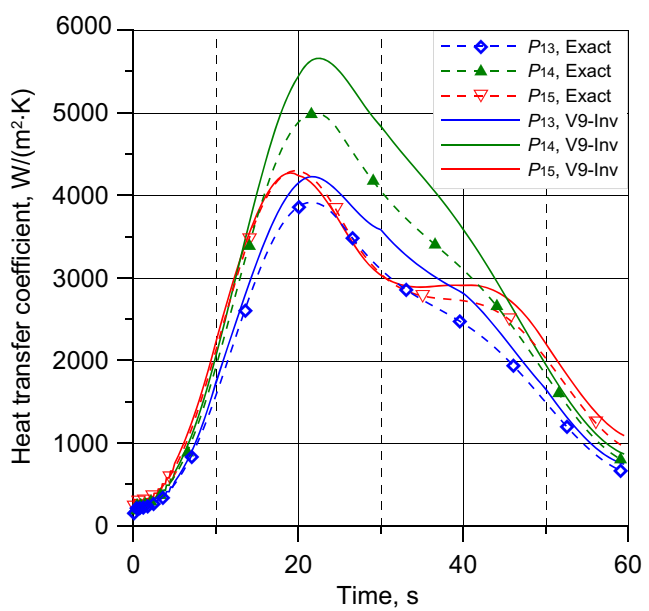

Fig. 16 The inverse solution obtained from the HTC model V9 at points: $P_{13}, P_{14}$ and $P_{15}$ compared to the exact data 


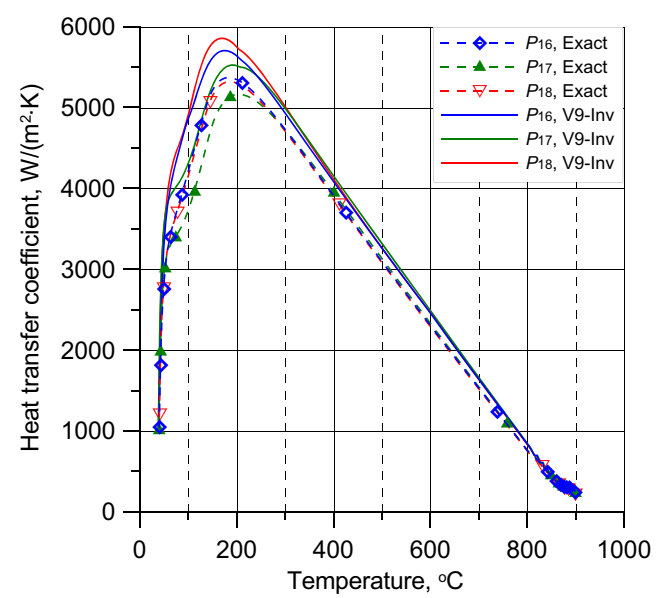

Fig. 17 The inverse solutions obtained from the HTC model V9 at points: $P_{16}, P_{17}$ and $P_{18}$ compared to the exact data

interpolated temperature sensors if the HTC surface degrees of freedom are higher than the number of physical thermocouples.

\section{Inverse solutions to the measured temperatures}

The inverse solutions to the measured temperatures obtained from transient cooling of the stationary plate have been performed mainly to address two numerical problems:

i) Effect of the reduction of the FEM solution to temperature field from $3 \mathrm{D}$ to $1 \mathrm{D}$ heat conduction on the accuracy of the HTC determination.

ii) Influence of the temperature sensor number and location on the accuracy of the $3 \mathrm{D}$ inverse solutions.

One of the first important problems in the inverse solutions which utilize gradient methods for the objective function

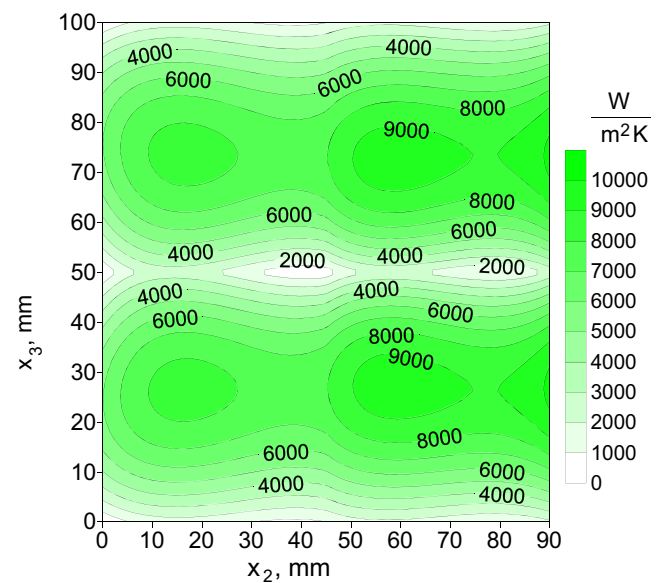

Fig. 18 The HTC distribution over the cooled surface at $\tau=30 \mathrm{~s}$. The HTC model V4. $\mathrm{HTC}_{\max }=10,253, \mathrm{HTC}_{\min }=23 \mathrm{~W} /\left(\mathrm{m}^{2} \cdot \mathrm{K}\right)$

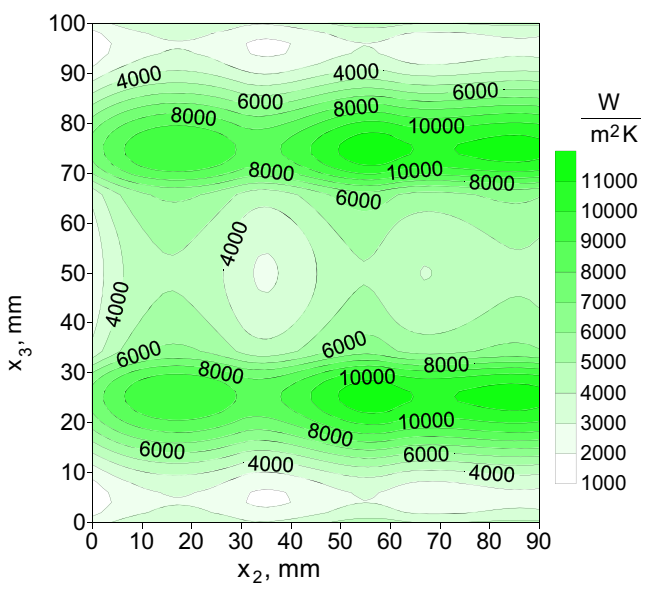

Fig. 19 The inverse solution to the HTC over the cooled surface at $\tau=30 \mathrm{~s}$. The HTC model V9. $\mathrm{HTC}_{\max }=11,685, \mathrm{HTC}_{\min }=1402 \mathrm{~W} /$ $\left(\mathrm{m}^{2} \cdot \mathrm{K}\right)$

minimization is a choice of a prior solution. The developed strategy [35] of the HTC approximation in space and time offers a natural choice for that. The vector of unknown $p_{\mathrm{i}}$ parameters is composed of sub-vectors which define the HTC distribution in time at nodes of surface elements. The HTC distributions at nodes of surface elements can be readily obtained from one dimensional inverse solution to the heat conduction problem in the plate. Such a prior solution has been improved using 3D models of heat conduction in the plate. In the $3 \mathrm{D}$ models of heat conduction prism elements with nonlinear shape functions of third degree have been utilized. The HTC determination zone has been divided into 25 prism elements. Only one element has been used over the plate thickness, Table 3. The tests of the finite element model presented in Table 3 have shown that the reduced models of heat conduction offer a good accuracy at a low number of freedoms. In the case of 25 prism elements the heat conduction model has only 576 unknowns.

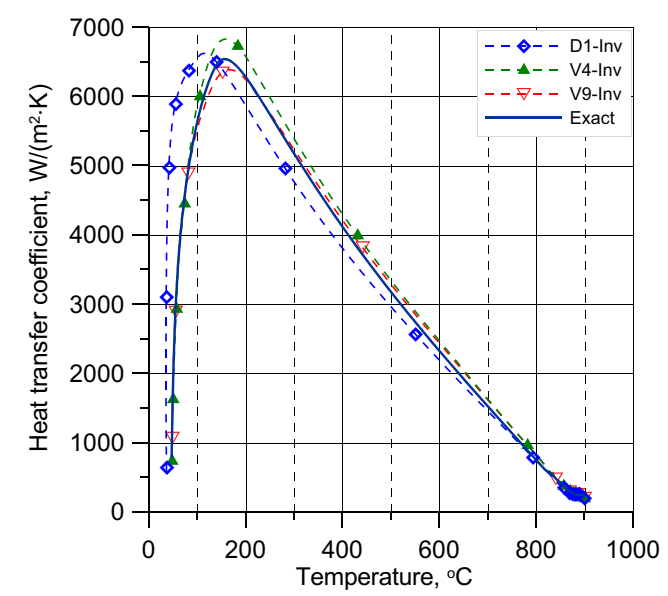

Fig. 20 The average over the surface HTC obtained from local 1D and $3 \mathrm{D}$ inverse solutions compared to exact data 


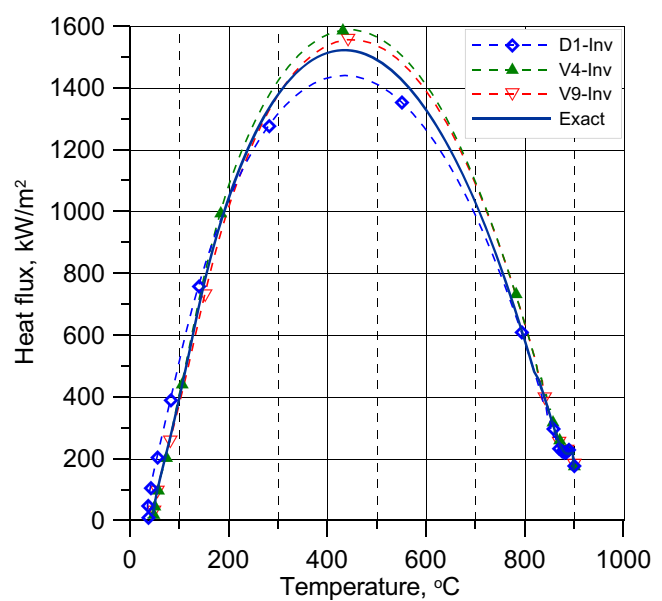

Fig. 21 The average over the surface heat flux obtained from local 1D and $3 \mathrm{D}$ inverse solutions compared to exact data

\subsection{The HTC model V4}

The HTC distribution in the inverse solutions V4-Inv to the measured temperatures has been approximated by 4 surface elements with cubic shape functions, Fig. 5. Expansion in time of the HTC at nodes of surface elements has been interpolated using 7 periods with cubic shape functions over each period for the plate cooling by six water jets, Fig. 2. It has given 726 $p_{i}$ parameters to be determined in the inverse solution to the boundary condition at the water cooled surface. A prior solution (D1-Inv) has already given a low ATD of $2.05^{\circ} \mathrm{C}$ with a maximum deviation $\Delta \mathrm{T}_{\mathrm{n}}=7.9^{\circ} \mathrm{C}$. The $3 \mathrm{D}$ inverse solution (V4-Inv) to the plate cooling by six water jets has converged to an ATD of $0.85{ }^{\circ} \mathrm{C}$, with a maximum deviation $\Delta \mathrm{T}_{\mathrm{n}}=4.3^{\circ} \mathrm{C}$. In Figs. 22 and 23 the measured temperatures at selected thermocouples locations have been compared to 1D and 3D inverse solutions. The differences between

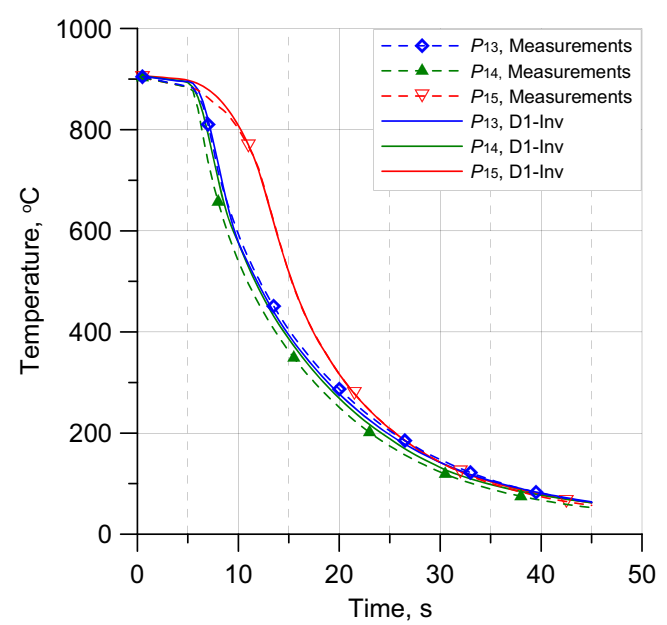

Fig. 22 The 1D inverse solutions to the temperature variations at points: $P_{13}, P_{14}, P_{15}$ compared to the measurements for the inconel plate cooling by six water jets

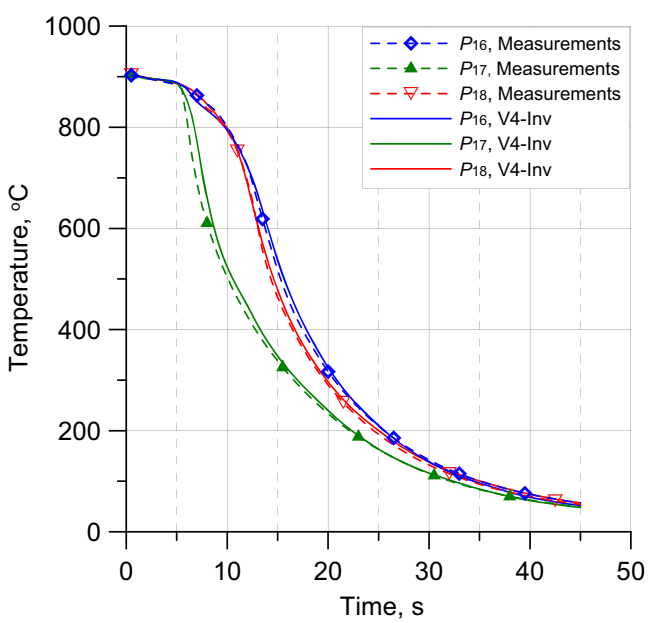

Fig. 23 The 3D inverse solution to the temperature variations at points: $P_{16}, P_{17}, P_{18}$ compared to the measurements for the inconel plate cooling by six water jets. The HTC model V4

computed and measured temperatures are negligible in both cases. However, the HTC distributions obtained from 1D heat conduction model, Fig. 24, differ significantly from those obtained from the 3D model, Fig. 25.

The plate cooling by water jets results in a very fast increase of the HTC as the plate surface temperature drops at point $P_{14}$ and $P_{16}$ located near the stagnation points. The plate temperature below the water jets (at stagnation points) decreases rapidly and the wetting zone in Fig. 26 visible as a dark spots grows. The wetting zone grows and the HTC maximum moves at point $P_{15}$ and $P_{17}$ to the surface temperatures much lower from the HTC maximum at points $P_{14}$ and $P_{16}$, Fig. 25. The 1D inverse solutions largely underestimate the HTC maxima at points $P_{14}$ and $P_{16}$ and overestimate at points $P_{15}$ and $P_{17}$. This drawback of the 1D inverse solution has been discussed in Section 5.2. The plate surface temperature after $10 \mathrm{~s}$ of cooling has been shown in Fig. 26. The water jets

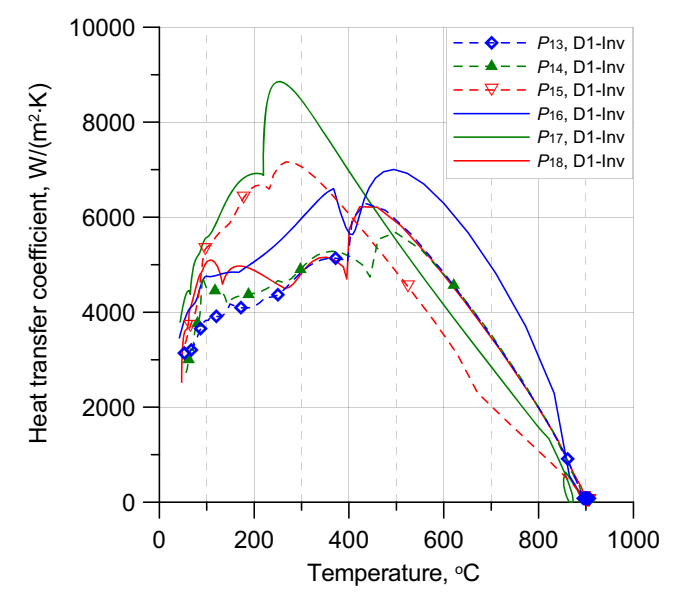

Fig. 24 The HTC distributions at points: $P_{13}, . ., P_{18}$ obtained from 1D inverse solutions for the inconel plate cooling by six water jets 


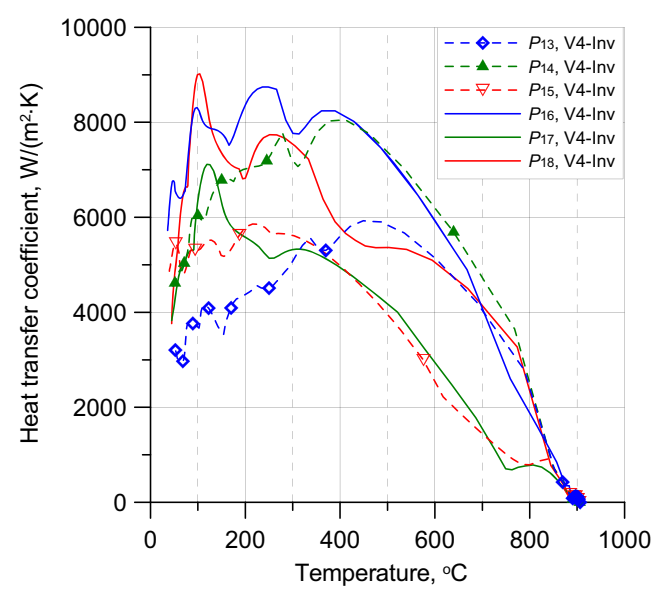

Fig. 25 The HTC distributions at points: $P_{13}, . ., P_{18}$ obtained from $3 \mathrm{D}$ inverse solution for the inconel plate cooling by six water jets. The HTC model V4

have partly merged and moved to the center of the plate. For that reason and due to low resolution of the HTC model V4 only three wetting zones can be recognized in Fig. 26. After about $10 \mathrm{~s}$ the HTC reaches a maximum value of $17,140 \mathrm{~W} /$ $\left(\mathrm{m}^{2} \cdot \mathrm{K}\right)$ at the plate surface, Fig. 27. At the same time the HTC minimum is of $45 \mathrm{~W} /\left(\mathrm{m}^{2} \cdot \mathrm{K}\right)$. In view of the uncertainty test shown in Section 5.3.1 the HTC can be essentially overestimated or underestimated due to low resolution of the HTC model V4.

\subsection{The HTC model V9}

The plate cooling by six water jets results in a highly non uniform heat transfer over the cooled surface. The implementation of 4 elements over the cooled surface did not allowed the HTC maxima for six water jets to be clearly identified. Higher number of degrees of freedom is required. The $3 \mathrm{D}$

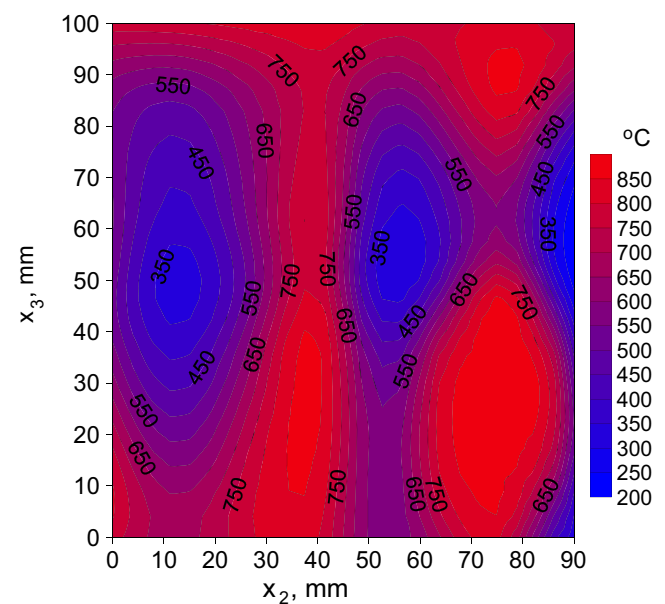

Fig. 26 The $3 \mathrm{D}$ inverse solution at $\tau=10 \mathrm{~s}$ to the plate surface temperature cooled by six water jets. $\mathrm{T}_{\max }=893, \mathrm{~T}_{\min }=205{ }^{\circ} \mathrm{C}$. The HTC model V4

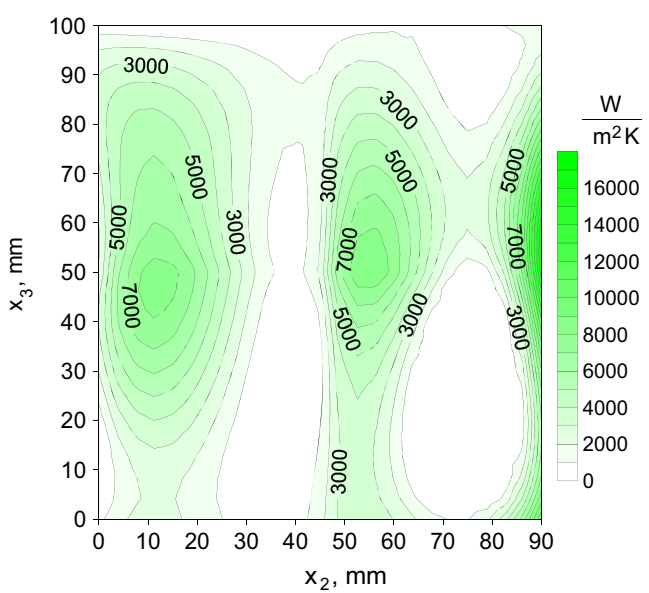

Fig. 27 The 3D inverse solution at $\tau=10 \mathrm{~s}$ to the HTC over the plate cooled by six water jets. $\mathrm{HTC}_{\max }=17,140, \mathrm{HTC}_{\min }=45 \mathrm{~W} /\left(\mathrm{m}^{2} \cdot \mathrm{K}\right)$. The HTC model V4

inverse solution with 9 elements over the cooled surface (V9-Inv) to the plate cooling has converged to an ATD of $0.55^{\circ} \mathrm{C}$, with a maximum deviation $\Delta \mathrm{T}_{\mathrm{n}}$ of $2.5^{\circ} \mathrm{C}$. In Fig. 28 the plate surface temperature after $10 \mathrm{~s}$ of cooling has been presented. The locations of the water jets can be recognized.

The inconel plate cooling by 6 water jets has allowed covering nearly the whole HTC determination domain by water streams. The plate temperature drops rapidly but varies from 292 to $861{ }^{\circ} \mathrm{C}$ over the surface after $10 \mathrm{~s}$ of cooling, Fig. 28. It causes high differences in the HTC distribution shown in Fig. 29. In the case of the HTC model V4 the difference between maximum and minimum temperature of the surface was $688^{\circ} \mathrm{C}$. The HTC model V9 has given much lower difference in the plate temperature equal to $569^{\circ} \mathrm{C}$. The locations of the water jets can be readily recognized from the HTC distribution after $10 \mathrm{~s}$ of cooling, Fig. 29.

The HTC reaches the maximum value above $12 \mathrm{~kW} /$ $\left(\mathrm{m}^{2} \cdot \mathrm{K}\right)$. The HTC variations versus temperature presented in

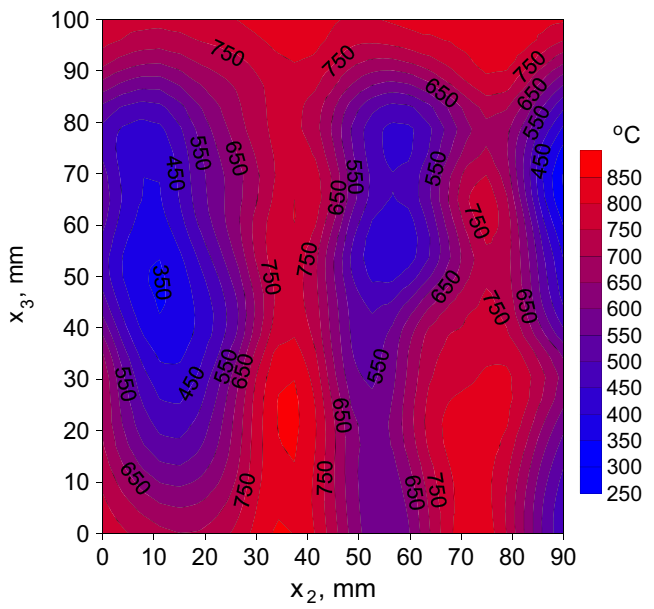

Fig. 28 The inverse solution at $\tau=10 \mathrm{~s}$ to the plate surface temperature cooled by six water jets. $\mathrm{T}_{\max }=861, \mathrm{~T}_{\min }=292^{\circ} \mathrm{C}$. The HTC model V9 


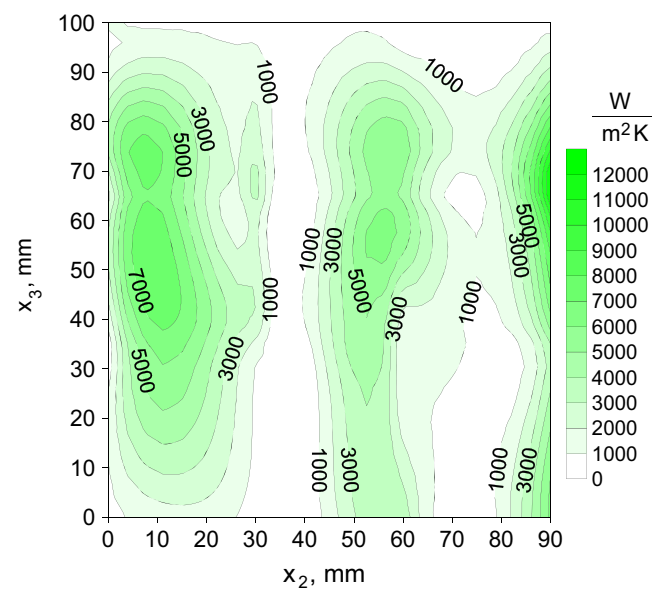

Fig. 29 The inverse solution at $\tau=10 \mathrm{~s}$ to the HTC over the plate cooled by six water jets. $\mathrm{HTC}_{\max }=12,025, \mathrm{HTC}_{\min }=50 \mathrm{~W} /\left(\mathrm{m}^{2} \cdot \mathrm{K}\right)$. The HTC model V9

Fig. 30 confirm that heat conduction is far from one dimensional. At some points $\left(P_{13}\right.$ and $\left.P_{18}\right)$ probably due to water movement essential decrease in the HTC during nucleate boiling have been obtained. The heat flux distributions presented in Fig. 31 as functions of time also confirm essential differences in heat transfer at selected points.

The heat flux maximum values vary from $20 \mathrm{MW} / \mathrm{m}^{2}$ at point $P_{15}$ to about $30 \mathrm{MW} / \mathrm{m}^{2}$ at point $P_{14}$ located at the stagnation zone shown in Fig. 28. The critical heat flux temperature varies from 400 to $500{ }^{\circ} \mathrm{C}$. But the connection of the critical heat flux temperature with the location of point is not clear. The obtained results for plate cooling with 6 water jets have shown that film boiling is limited to about $3 \mathrm{~s}$. Distance between jets was only $40 \mathrm{~mm}$ and kinetic energy of the water stream was sufficient to disrupt the vapor film at the surface temperature of about $870{ }^{\circ} \mathrm{C}$. Transition boiling takes place nearly from the beginning of cooling up to critical heat flux.

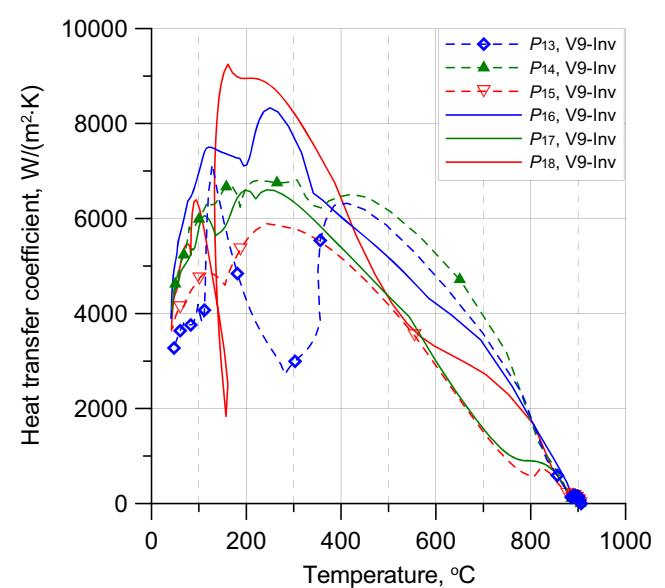

Fig. 30 The HTC distributions at points: $P_{13}, . ., P_{18}$ obtained from 3D inverse solution for the inconel plate cooling by six water jets. The HTC model V9

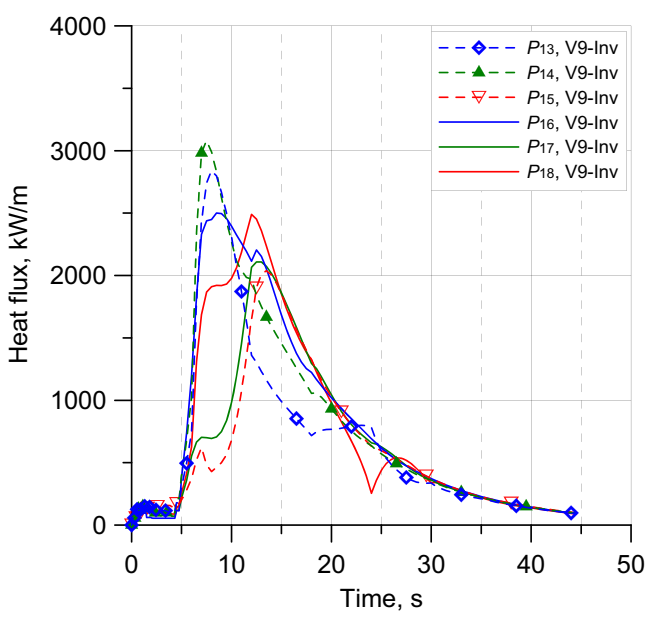

Fig. 31 The heat flux distributions at points: $P_{13}, . ., P_{18}$ obtained from 3D inverse solution for the inconel plate cooling by six water jets. The HTC model V9

Time of cooling to critical heat flux depends on the distance from the stagnation point. Near the stagnation points critical heat flux develops in 2 to $3 \mathrm{~s}$. The longest time of cooling to critical heat flux was about $7 \mathrm{~s}$. During nucleate boiling heat flux decreases as the plate surface temperature approaches the saturation temperature. After $25 \mathrm{~s}$ of cooling the heat flux is similar at all the analyzed points. Due to unpredictable water flow during nucleate boiling heat flux may drop at some points, for example at point $P_{15}$. It leads to increase in the surface temperature and the heat flux increases after some time. In the case of the HTC plotted versus the plate surface temperature this phenomenon is visible as the HTC loop, Fig. 30, point $P_{15}$.

The presented above short discussion of plate cooling with water jets do not explains several important aspects related to water cooling. The description of physical aspects of heat transfer related to similar problem of water jet cooling under steady state conditions has been given by Robidou et al. [39]. The transition from nucleate boiling to film boiling under variable water velocity and distance from the nozzle to plate surface has been discussed. The influence of superheat and subcooling on the heat flux has been reported as well. Grows of wetting zone under transient cooling of a plate with a water jet has been studded by Mitsutake and Monde [25]. Another important factor related to strip cooling in hot rolling lines is the influence of the strip velocity on the heat transfer. Influence of the surface motion on the heat flux has been studied by Gradeck et al. [40] using water jet impinging on a rotating cylinder. This problem is probably the most complicated due to difficulties with the experiment and with the interpretation of the inverse solution in the coordinate system fixed with the water jet. Review of the recent development of jet cooling can be found in the paper by Qiu et al. [19].

The average HTC calculated from the HTC distribution over the cooled surface has been presented in Fig. 32. The 


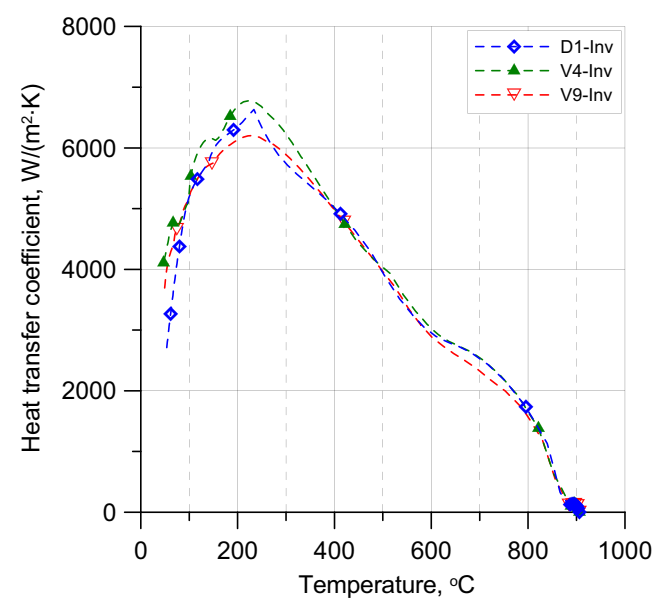

Fig. 32 Average HTC over the HTC determination zone versus average temperature, obtained from the local 1D and 3D inverse solutions

local 1D inverse solutions at surface element nodes have given nearly the same average HTC as 3D inverse solutions. In the case of 1D solution the HTC maximum is slightly higher of about $7 \%$. The maxim value of $6.2 \mathrm{~kW} /\left(\mathrm{m}^{2} \mathrm{~K}\right)$ has been obtained from the HTC model V9. The HTC maxima from 1D and $3 \mathrm{D}$ inverse solutions have been obtained for the same average surface temperature of $230^{\circ} \mathrm{C}$. The average heat flux over the cooled surface is very similar for 3D solutions utilizing 4 and 9 elements over the surface, Fig. 33. In the case of 1D inverse solution the heat flux maximum has been overestimated of about $10 \%$. But the dependence of surface temperature has been correctly identified even from 1D solutions. The HTC model V9 has given the heat flux maximum of $16.7 \mathrm{MW} / \mathrm{m}^{2}$ at a surface temperature of $470{ }^{\circ} \mathrm{C}$. The maximum value of the average heat flux is nearly $50 \%$ lower than the heat flux maximum at point $P_{14}$. It means that the plate cooling with 6 water jets is far from uniform.

The obtained solution for the inconel plate cooling with 6 water jets is difficult to compare with earlier research mainly

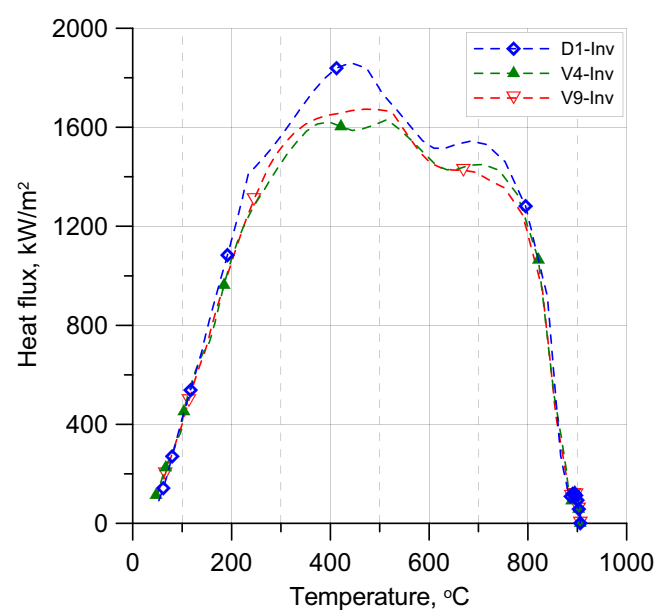

Fig. 33 Average heat flux over the HTC determination zone versus average temperature obtained from the local $1 \mathrm{D}$ and $3 \mathrm{D}$ inverse solutions due to differences in the water flow rate and arrangement of jets and sample temperatures. Wang et al. [29] has reported the HTC maxim at stagnation point of about $4.5 \mathrm{~kW} /\left(\mathrm{m}^{2} \mathrm{~K}\right)$ for AISI $304 \mathrm{~L}$ steel cooling with one water jet. The water flow rate was $15 \mathrm{dm}^{3} / \mathrm{min}$. Our solution has given the HTC maximum at points $P_{13}$, to $P_{18}$ ranging from 6 to $7 \mathrm{~kW} /\left(\mathrm{m}^{2} \mathrm{~K}\right)$ for water flow rate $10.4 \mathrm{dm}^{3} / \mathrm{min}$. The differences are essential and can result from the inverse solution method. Since the uncertainty test has not been provided it is impossible to point out further reasons for differences. Mitsutake et al. [25] has reported the maximum heat flux of $1.9 \mathrm{MW} / \mathrm{m}^{2}$ for steel cooling with one water jet. In our solution the maximum heat flux at points $P_{13}$, to $P_{18}$ ranged from 2 to $3 \mathrm{MW} / \mathrm{m}^{2}$. The sample was heated to $250^{\circ} \mathrm{C}$ only. The results are comparable taking into account the difference in the initial temperature of samples.

The obtained results from stationary plate cooling may have some practical implementation as boundary conditions for modeling of steel cooling. However, development of a local boundary condition suitable for modeling strip cooling at run-out table of the hot rolling lines is a much more complicated problem. Photo of the run-out table in the hot rolling line has been published by Gradeck et al. [40]. At the strip surface dark lines are visible resulting from the local strip overcooling by the circular water jets. This phenomenon is well known for our research team. The problem can be solved using FEM simulation with the local boundary conditions. However, the procedure leading to development of a local boundary condition written in the coordinate system fixed with the jet needs several steps. One of the possible strategies could involve:

i) Identification of the local HTC based on 3D inverse solutions obtained from stationary plate cooling under various parameters.

ii) Selection of a suitable model describing the HTC as function of surface temperature, distance from the jet, water flow rate and/or other important parameters.

iii) Identification of the HTC approximating function parameters based on the set of the HTC coefficients obtained from the step i).

iv) Implementation of the boundary condition into the 3D heat condition solver and validation of the boundary condition model based on temperature measurement obtained during stationary and/or moving plate cooling.

v) Implementation of the local boundary condition into the 3D FEM code suitable for modeling of the strip cooling in run-out table under local boundary conditions.

vi) Validation of the obtained strand temperature based on data from the industrial on-line measurement system.

The model of the strip cooling in hot rolling line utilizing average in zones boundary conditions has been reported by 
Edalatpour et al. [41]. The model of strip cooling in the impingement zones takes into account the strip velocity. The predicted temperatures of the strips have been compared to the results obtained from pyrometers located at exit of runout table. The measurements have been compared to the results of simulation for 97 strips. The predicted strip temperature error was below $17{ }^{\circ} \mathrm{C}$. Other type of model for strip cooling in run-out table has been developed by Gomez et al. [42]. The HTC model developed by Hodgson et al. [43] has been employed in zones of cooling. The Hodgson et al. formula gives the boiling curve which depends on the strip surface temperature and the water flow rate only. The model predictions have been compared to the large set of temperature measurements from pyrometers. The error was below $20^{\circ} \mathrm{C}$ in most cases. Thus the average in zones boundary conditions of the essentially different type give a possibility to determine the average strip temperature at the end of cooling line with acceptable accuracy. Correction of the existing models of strip cooling based on on-line temperature measurement system is sufficient to reach that goal. But the microstructure evolution processes and fracture of metals depend on local temperature and for that reason development of a local bounder condition is important. To the best of our knowledge the FEM models of strip cooling at run-out table based on a local boundary condition have not been developed yet. However, the strand cooling in continuous casting line has been already modeled using a local boundary condition for water spray cooling specified at each spray nozzle [44].

\section{Conclusions}

All the inverse solutions to the water jets cooling have given very low temperature differences between measured and computed temperatures. However, a good agreement between measured and computed temperatures can be obtained for several variants of the HTC distribution in time and space. The choice of the correct solution may not be obvious or simple. The selection of the correct result can be done based on uncertainty tests. The test function should model the real cooling experiment as good as possible. Locations of the HTC maxima in space and versus temperature are essential for reliable uncertainty tests.

One dimensional inverse solution at thermocouple location results in overestimation of the HTC at points having higher temperature and underestimation of the HTC at colder places. The error depends on the temperature gradients in space and has reached $35 \%$ for the considered water jets cooling. But the one dimensional inverse solution at nodes of surface elements is the best choice of a prior solution for the objective function minimization in the three dimensional inverse heat conduction models.
The three dimensional inverse solution having limited number of degrees of freedom may not improve a prior solution essentially. The implementation of 4 surface elements with 33 nodes did not give essentially better solution. The inverse solution utilizing 9 surface elements with 64 nodes has reduced the local error to the HTC estimation to about $20 \%$. However, for 30 thermocouples it was necessary to constrain the inverse solution with the interpolated temperature sensors. The extension of the physical thermocouples with the interpolated temperature sensors has allowed obtaining higher resolution to the HTC distribution over the plate surface.

The conducted physical experiment has shown that the HTC maxima move essentially over the plate surface due to several reasons. In such a case the distance between physical thermocouples should be reduced. The arrangement of the physical thermocouples in an array of $7 \times 7$ sensors should be considered in further research. The numerical simulations of the plate temperature with and without thermocouples have shown that the distance of $15 \mathrm{~mm}$ between thermocouples having diameter of 0.5 is sufficient for a correct thermocouple reading.

Acknowledgements Scientific study financed from the regular activity of the Faculty of Metals Engineering and Industrial Computer Science of AGH University of Science and Technology.

\section{Compliance with ethical standards}

Conflict of interest On behalf of all authors, the corresponding author states that there is no conflict of interest.

Open Access This article is distributed under the terms of the Creative Commons Attribution 4.0 International License (http:// creativecommons.org/licenses/by/4.0/), which permits unrestricted use, distribution, and reproduction in any medium, provided you give appropriate credit to the original author(s) and the source, provide a link to the Creative Commons license, and indicate if changes were made.

\section{References}

1. Mohib M, Rehman Ur QZG, Fu RP, Xu HT (2017) Numerical study on free-surface jet impingement cooling with nanoencapsulated phase-change material slurry and nanofluid. Int J Heat Mass Transf 109:312-325

2. Yang L, Ren J, Jiang H, Ligrani P (2014) Experimental and numerical investigation of unsteady impingement cooling within a blade leading edge passage. Int J Heat Mass Transf 71:57-68

3. Jung EY, Chung H, Choi SM, Woo T, Cho HH (2017) Conjugate heat transfer on full-coverage film cooling whit array jet impingements with various Biot numbers. Exp Thermal Fluid Sci 83:1-8

4. He YL, Wen ZX (2017) Experimental study on cooling performance of multiple impinging jets with different nozzle arrangements in a ground fast cooling simulation device. Appl Therm Eng 113:1024-1032

5. Kheirabadi AC, Groulx D (2016) Cooling of server electronics: A design review of existing technology. Appl Therm Eng 105:622638 
6. Anwarullah M, Vasudeva Rao V, Sharma KV (2012) Experimental investigation for enhancement of heat transfer from cooling of electronic components by circular air jet impingement. Heat Mass Transf 48:1627-1635

7. Končar B, Norajitra P, Oblak K (2010) Effect of nozzle sizes on jet impingement heat transfer in He-cooled divertor. Appl Therm Eng 30:697-705

8. Li X, Wang M, Du F (2005) A coupled thermal mechanical and microstructural FE model for hot strip continuous rolling process and verification. Mater Sci Eng A 408:33-41

9. Bambach M, Seuren S (2015) On instabilities of force and grain size predictions in the simulation of multi-pass hot rolling processes. J Mater Process Technol 216:95-113

10. Nobari AH, Prodanovic V, Militzer M (2016) Heat transfer of stationary steel plate during water jet impingement cooling. Int J Heat Mass Transf 101:1138-1150

11. Horský J, Raudenský M, Kotrbáček P (1998) Experimental study of long product cooling in hot rolling. J Mater Process Technol 80-81: 337-340

12. Han HN, Lee JK, Kim HJ, Jin YS (2002) A model for deformation, temperature and phase transformation behavior of steels on run-out table in hot strip mill. J Mater Process Technol 128:216-225

13. Panjkovic V (2007) Model for prediction of strip temperature in hot strip steel mill. Appl Therm Eng 27:2404-2414

14. Olejarczyk I, Adrian A, Adrian H, Mrzygłód B (2010) Algorithm for controlling of quench hardening process of constructional steels. Arch Metall Mater 55:171-179

15. Kim J (2007) Spray cooling heat transfer: The state of the art. Int J Heat Fluid Flow 28:753-767

16. Abbasi B, Kim J, Marshall A (2010) Dynamic pressure based prediction of spray cooling heat transfer coefficients. Int J Multiphase Flow 36:491-502

17. Slayzak SJ, Viskanta R, Incropera FP (1994) Effects of integration between adjacent free surface planer jets on local heat transfer from the impingement surface. Int J Heat Mass Transf 37:269-282

18. Freund S, Pautsch AG, Shedd TA, Kabelac S (2007) Local heat transfer coefficients in spray cooling systems measured with temperature oscillation IR thermography. Int J Heat Mass Transf 50: 1953-1962

19. Qiu L, Dubey S, Choo FH, Duan F (2015) Recent developments of jet impingement nucleate boiling. Int J Heat Mass Transf 89:42-58

20. Beck JV (1970) Nonlinear estimation applied to the nonlinear inverse heat conduction problem. Int J Heat Mass Transf 13:703-716

21. Singh MK, Yadav D, Arpit S, Mitra S, Saha SK (2016) Effect of nanofluid concentration and composition on laminar jet impinged cooling of heat steel plate. Appl Therm Eng 100:237-249

22. Cebo-Rudnicka A, Malinowski Z, Buczek A (2016) The influence of selected parameters of spray cooling and thermal conductivity on heat transfer coefficient. Int J Therm Sci 110:52-64

23. Agrawal C, Kumar R, Gupta A, Chatterjee B (2013) Determination of rewetting on hot horizontal surface with water jet impingement through a sharp edge nozzle. Int J Therm Sci 71:310-323

24. Malinowski Z, Cebo-Rudnicka A, Telejko T, Hadała B, Szajding A (2015) Inverse method implementation to heat transfer coefficient determination over the plate cooled by water spray. Inverse Probl Sci Eng 23:518-556

25. Mitsutake Y, Monde M (2001) Heat transfer during transient cooling of high temperature surface with an impinging jet. Heat Mass Transf 37:321-328

26. Robidou H, Auracher H, Gardin P, Lebouche M, Bogdanic L (2003) Local heat transfer from a hot plate to a water jet. Heat Mass Transf 39:861-867
27. Jha JM, Ravikumar SV, Sarkar I, Pal SK, Chakraborty S (2015) Ultrafast cooling process with surfactant additive for hot moving steel plate. Exp Thermal Fluid Sci 68:135-144

28. Sarkar I, Behera DK, Jha JM, Pal SK, Chakraborty S (2016) Effect of polymer additive on the cooling rate of a hot steel plate by using water jet. Exp Thermal Fluid Sci 70:105-114

29. Wang H, Yu W, Cai Q (2012) Experimental study of heat transfer coefficient on hot steel plate during water jet impingement cooling. J Mater Process Technol 212:1825-1831

30. Agrawal C, Gotherwal D, Singh C, Singh C (2017) Effect of surface thickness on the wetting front velocity during jet impingement surface cooling. Heat Mass Transf 53:733-741. https://doi.org/10. 1007/s00231-016-1855-9

31. Huang CH, Wang SP (1999) A three dimensional inverse heat condition problem in estimating surface heat flux by conjugate gradient method. Int J Heat Mass Transf 42:3387-3403

32. Kim SK, Lee JS, Lee WI (2003) A solution method for a nonlinear three-dimensional inverse heat conduction problem using the sequential gradient method combined with cubic-spline function specification. Numer Heat Transf Part B 43:43-61

33. Zhou J, Zhang Y, Chen JK, Feng ZC (2012) Inverse estimation of front surface temperature of a plate with laser heating and convection-radiation cooling. Int J Therm Sci 52:22-30

34. Malinowski Z, Telejko T, Hadała B, Cebo-Rudnicka A, Szajding A (2014) Dedicated three dimensional numerical models for the inverse determination of the heat flux and heat transfer coefficient distributions over the metal plate surface cooled by water. Int $\mathrm{J}$ Heat Mass Transf 75:347-361

35. Hadała B, Malinowski Z, Szajding A (2017) Solution strategy for the inverse determination of the specially varying heat transfer coefficient. Int J Heat Mass Transf 104:993-1007

36. Çengel YA (2007) Heat and mass transfer: a practical approach, third edition. McGraw-Hill, New York

37. Goldsmith A, Waterman TE, Hirschhorn HJ (1962) Handbook of thermophysical properties of solid materials. Pergamon Press, New York

38. Zienkiewicz OC, Taylor RL (2000) The finite element method volume 1: the basis, fifth edition. Butterworth-Heinemann, Jordan Hill

39. Robidou H, Auracher H, Gardin P, Lebouché M (2002) Controlled cooling of a hot plate with a water jet. Exp Thermal Fluid Sci 26: 123-129

40. Gradeck FM, Kouachi A, Lebouché M, Volle F, Maillet D, Borean JL (2009) Boiling curves in relation to quenching of a high temperature moving surface with liquid jet impingement. Int $\mathrm{J}$ Heat Mass Transf 52:1094-1104

41. Edalatpour S, Saboonchi A, Hassanpour S (2011) Effect of phase transformation latent heat on prediction accuracy of strip laminar cooling. J Mater Process Technol 201:1776-1782

42. Gomez G, Schicht J, Perez T, Goldschmit M, Vigliocco A (2006) Thermo-metallurgical model of the cooling table for a flat product hot rolling mill. Proceedings from the materials science and technology conference, Cincinnati, Ohio pp 1677-1687

43. Hodgson PD, Browne KM, Collinson DC, Pham TT, Gibbs RK (1991) A mathematical model to simulate the thermo-mechanical processing of steel. Proceedings of $3^{\text {rd }}$ international seminar of the international federation for heat treatment and surface engineering, Melbourne pp 139-159

44. Hadała B, Malinowski Z, Telejko T (2016) Analysis of the slab temperature, thermal stresses and fractures computed with the implementation of local and average boundary conditions in the secondary cooling zones. Arch Metall Mater 61:2027-2036 